Copy № $\quad 19$

APAE Memo - 318

AEC Research and

Development Repnrt

UC-81, Reactors - Power

[Special Distribution]

\title{
mathematical analysis of rippling of type 1 fuel plates, part I
}

Contract No. AT[30-1]-2639

with U. S. Atomic Energy Commission

New York Operations Office

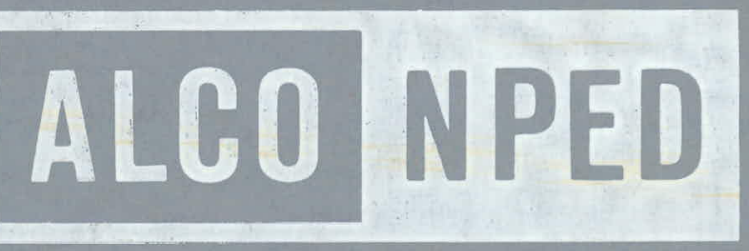

ALCO PRODUCTS, INC. NUCLEAR POWER ENGINEERING DEPARTMENT 


\section{DISCLAIMER}

This report was prepared as an account of work sponsored by an agency of the United States Government. Neither the United States Government nor any agency Thereof, nor any of their employees, makes any warranty, express or implied, or assumes any legal liability or responsibility for the accuracy, completeness, or usefulness of any information, apparatus, product, or process disclosed, or represents that its use would not infringe privately owned rights. Reference herein to any specific commercial product, process, or service by trade name, trademark, manufacturer, or otherwise does not necessarily constitute or imply its endorsement, recommendation, or favoring by the United States Government or any agency thereof. The views and opinions of authors expressed herein do not necessarily state or reflect those of the United States Government or any agency thereof. 


\section{DISCLAIMER}

Portions of this document may be illegible in electronic image products. Images are produced from the best available original document. 
APAE Memo-318

AEC Research and

Development Report

UC-81, Reactors, Power

(Special Distribution)

\title{
MATHEMATICAL ANALYSIS OF RIPPIING \\ OF TYPE I FUEL PLATES, PART I
}

\author{
By \\ S. D. Beck \\ J. V. Miller
}

Approved by:

E. W. Schrader, Acting Project Engineer

Issued: July 5,1962

Contract No. AT (30-1)-2639

with United States Atomic Energy Commission

New York Operations Office

ALCO PRODUCTS, INCORPORATED

Nuclear Power Engineering Department

Post Office Box 414

Schenectady 1, N. Y. 
$\underline{\text { AEC LEGAL NOTICE }}$

This report was prepared as an account of Government sponsored work. Neither the United States, nor the Commission, nor any person acting on behalf of the Commission:

A. Makes any warranty or representation, expressed or implied, with respect to the accuracy, completeness, or usefulness of the information contained in this report, or that the use of any information, apparatus, method, or process disclosed in this report may not infringe privately owned rights:

B. Assumes any liabilities with respect to the use of, or for damages resulting from the use of any information, apparatus, method, or process disclosed in this report.

As used in the above, "person acting on behalf of the Commission" includes any employee or contractor of the Commission, or employee of such contractor, to the extent that such employee or contractor of the Commission, or employee of such contractor prepares, disseminates, or provides access to, any information pursuant to his employment or contract with the Commission, or his employment with such contractor.

\section{ALCO LEGAL NOTICE}

This report was prepared by Alco Products, Incorporated in the course of work under, or in connection with, Contract No.AT(30-1)-2639, issued by U.S. Atomic Energy Commission, NYOO; and subject only to the rights of the United States, under the provisions of this contract, Alco Products, Incorporated makes no warranty or representation, express or implied, and shall have no liability with respect to this report or any of its contents or with respect to the use thereof or with respect to whether any such use will infringe the rights of others. 


\section{DISTRIBUTION}

External

Copies

$1-2$ New York Operations Office

U. S. Atomic Energy Commission

376 Hudson Street

New York 14, New York

NLLH: :- I\%M : Adlei

3

New York Operations Office

U . S. Atomic Energy Commission

376 Hudson Street

New York 14, New York

Attn: Library

4 - 6 U. S. Atomic Energy Commission

Washington 25, D. C.

Attn: Chief, Water Systems Project

Branch (Army Reactors)

Division of Reactor Development

Mail Station F-311

7

U. S. Atomic Energy Commission

Washington $25, \mathrm{D}$. C .

Attn: Chief, Evaluation and

Planning Branch

Civilian Reactors

Div. of Reactor Development

Mail Station. F-311

8. U.S.Atomic Energy Commission

Chief, New York Patent Group

Brookhaven National Laboratory

Upton, New York

Attn: Harman Potter 
External

Copies

9

Idaho Nuclear Power Field Office

U. S. Army Eng, Reactors Group

P. O. Box $2108^{\prime}$

Idaho Falls, Idaho,

10 U. S. Atomic Energy Commission

Reports and Statistics Branch

Division of Reactor Development

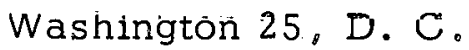

1.1. 12 Office of the Chief of Engineers

Department of the Army

Building $\mathrm{T}-7$

Washington 25, D. C.

Attn: Chief, Projects Branch Nuclear Power Division

$13-15 \quad$ Nuclear Power Field Office

U. S.Army Engineer Reactors Group

Fort Belvoir, Virginia

Attn: Chiet, Nuclear Power

Field Office

16 Nuclear Power Field Office

U. S. Army Engineer Reactors Group

Fort Belvoir, Virginia

Attn: $\quad \mathrm{O} \circ \mathrm{I} . \mathrm{C} \cdot \mathrm{SM}-\mathrm{l}$

17 Chief, U. S. Army Reactors Group

Fort Greely, Alaska

APO 733

Seattle, Washington

Attn: O.I.C. SM-1A

18 Commanding Officer

U. S. Army Polar Research

and Development Center

Fort Belvoir, Virginia

Attn: Nuclear Power Officer 


\section{DISTRIBUTION (CONT'D)}

External

Copies

$19-21$ Office of Technical Information Extension

P. O. Box 62

Oak Ridge, Tennessee

22 Union Carbide Nuclear Corporation

Oak Ridge National Laboratory

$Y=12$ Bullding 9704-1

P. O. Box "Y"

Oak Ridge, Tennessee

Attn: L. D. Schaffer

23 The Martin Company

P.O. Box 5042

Middle River, Maryland.

Attn: AEC Contract Document Custodian

$24-25 \quad$ Combustion Engineering, Incorporated

Nuclear Division

Prospect Hill Road

Windsor, Connecticut

Attn: $\mathrm{Mr}$. J. B. Anderson

Internal

Copies

R. Bell

K. Kasschau

J. F. Haines

J." G. Gallagher

P. E. Bobe

W.T. Williams

F. T. Matthews

C. Klotz

I. 'Segalman

W. M. S. Richards
J.V. Miller

S. D. Beck

J. A. Christenson

R. E. Neville

NPED File

Dr. F. F。 Ling

Dept. of Mechanics.

Renssalear Polytechnic

Institute

Troy, New York 


\section{THIS PAGE}

WAS INTENTIONALLY

LEFT BLANK 


\section{ABSTRACT}

Rippling phenomena due to heating in fuel plates of SM and PM type reactors are investigated analytically using small deflection theory of plates . Temperature variations across the width of the plate are accounted. for. Detailed calculations are conducted for simply supported plates. It is found that within the limitations imposed by small deflection theory that the amplitude of the plate ripples induced by the heating is directly proportional to the initial amplitude.

\section{ACKNOWLEDGMENT}

The authors wish to express their sincere appreciation to Dr. F. F. Ling of Rensselaer Polytechnic:Instïtute for his many helpful suggestions and comments and to the Alco staff members I. Segalman and J. G. Gallagher who have contributed significantly to this investigation. 


\section{THIS PAGE}

WAS INTENTIONALLY

LEFT BLANK 
ABSTRACT - - - - - - - - - - - - - - - - - - - - - -

ACKNOWLEDGMENT $\ldots \ldots \ldots$

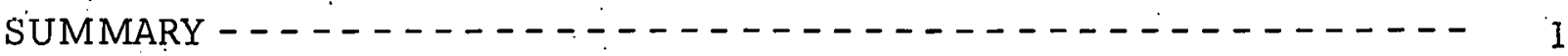

1.0 INTRODUCTION $-\cdots-\cdots-\cdots-\cdots-\cdots-\cdots-\cdots$

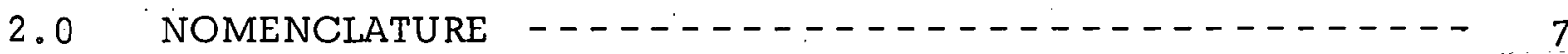

3.0 RIPPLING ANATYYSIS USING SMALL DEFLECTION THEORY - - - - 9

3.1 Assumptions and Mathematical Results - - - - - - 9

3.2 Derivation of Results From Small Deflection Theory - - - - 12

4.0. APPLICATION OF MATHEMATICAL MODEL - - - - - - - - - - . 15

4.1. Summary of Equations - - - - - - - $-\cdots-\cdots---15$

4.2 Critical Loading Factor - - - - - - - -15

4.3 Temperature Induced Loads $-\ldots-\ldots-\ldots$

4.4. Amplification Factor - - - - - - 19

4.5 SM-1A Temperature Bistribution - - - - - - - - - - , 21

5.0 FUTURE WORK - - - - - - - - - - - - - - - - - - 27

5.1 Characteristics of Large Deflection. Theory $---_{----} \quad 27$

6.0 REFERENCES - - $\ldots \ldots-\ldots \ldots \ldots$

APPENDIX A - Bibliography - - - - - - - - - - $--\cdots-----\quad 31$

APPENDIX B - Review of Existing Data and Application to Thermal Analysis -.- $-\ldots-\ldots-\ldots 7$

B.1 General Considerations - - - - - - - - - - - - - 39

B. I. I Small Deflection Theory - - - - - - $---\cdots$ 
B.1.2. Fuel Plate Support - -

B.1.3 Mechanical Properties - - - - - - - - - 40

$B_{\circ ;}$ 1.4: Adjacent Fuel Plate Rippling - - - - - - - - 40

B.2 Initial Distortion -

B.2.1 Manufacturing Tolerances - - - - - - - - 40

B.2.2 Number of Ripples Per Plate -

B.2.3 End-of-Life Initial Distortion - - - - - - - 43

B.2.4 Ripple Amplification Factor - - - - - - - - : 46

B.3 Application to Thermal Analysis - - - - $-\cdots$

B.3.1 Description of Rippled Coølant Channel-:---:- 48

B:3.2 Thermal Analysis of the Rippled Channel - - - - 48

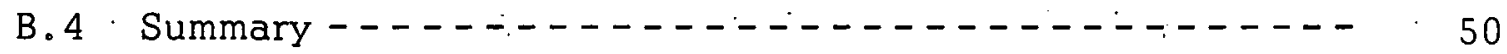

B.5 Appendix References - - - - $5-\cdots--\cdots-\ldots$ 


\section{LIST OF ILLUSTRATIONS}

Figure

Title

Page

$1 \quad$ Fixed Element With End Box Removed

2 Fuel Plate Distortion Resulting From Thermal Stresses

3 Cross-Section of Fuel Plate With its Associated Element of Side Plate

4 Temperature Distrihutions Usod in Cumiparlson Study

5 Comparison of Stress Distributions Induced by Thermal Loading

6 Comparison of Deflection Ratios Caused by Various

Temperature Distributions

$7 \quad$ Typical SM- 1 A Temperature Distribution

8 Comparison of Analytic and Experimental Rippling Amplification Factor

B. 1 Schematic Representation of Internal Channels and Lattice Channel Longitudinal View

B.2 Initial Rippling of Element 17-SM-1A

B.3 Initial Rippling of Element 23-SM-1A

B. 4 Schematic of Rippled Coolant Channel Under Operating Conditions 
Based on small deflection theory, equations have been derived for a rippled fuel plate which predict the final plate deflection as a function of initial conditions and operating temperature differences. These equations have been used to check tests which have been previously performed on single fuel plates.

In the range of SM-1A operating conditions there is good agreement between the analytical solution and the test results. It appears, therefore, that the equations presented here can be used with a fair degree of confidence for predirting the platc dcfleetiuns uf Type 1 fuel elements. However, a more extensive comparison between the analytical model and available test results is required to substantiate this supposition. This should include a comparison with the proposed multi-plate test $(5)$ so that the effect of the side plate restraints can be evaluated.

Additional comparisons have been made on fuel plates with various temperature distributions and show that temperature profiles which are peaked the center of the plate are more severe than those in which the maximums occur : nearer to the edge of the plate.

An outline is also presented on the use of large deflection theory for the solution of this problem. It is pointed out that for an accurate estimate of the amplitude of plate deflections resulting from rippling, the large deflection theory is required if the amplitude exceeds the plate thickness:

Appendix $B$ reviews the existing experimental and manufacturing information relevant to the rippling problem and predicts the appearance of a lattice coolant channel which is enclosed between two rippled fuel plates. To define this "hot" channel the available information was coupled with test results and the analytical solution presented in the body of this report. Thus it has been shown that the derived equations can be used with manufacturing data to conservatively predict the channel closure resulting from rippling. A thermal analysis can then be performed to determine the effect on core performance. 
THIS PAGE

WAS INTENTIONALLY

LEFT BLANK 


\subsection{INTRODUCTION}

The object of this investigation is to develop a technique to accurately predict the fuel plate ripple growth and the thermal safety of the various SM and PM type cores. This investigation is important because of the relatively thin plates (0.030 in. Types 1 and 2 and 0.040 in. Type 3) used in SM-1, SM-1A, PM-2A, SM-2 and PL-3 reactors and the observed magnitude of ripples in the SM-1 Core 1 elements. The initial investigation of thermal safety is to be performed for the SM-1A which operates at an average power density of 144 watts/cc。

This report covers the initial mathematical investigation of fuel plate rippling. A companion report (5) covers the initial laboratory investigation.

Rippling of plate type fuel elements is defined as the occurrance of irregular surfaces on a flat plate when subjected to compressive forces in the plane of the plate. These stresses usually produce a sinusoidal "washboard" buckling in the longitudinal plane of the plate. Figure 2 shows the characteristic shapes resulting from rippling. This is a potentially serious problem in the thin (30 to 40 mils) fuel plates which are used in present ALCO designed reactors.

In the SM-1A brazed Type 1 and 2 fuel elements (Fig. 1) an initial ripple occurs in manufacturing because of the heating and cooling rates associated with the brazing cycle. This initial ripple is usually aggravated on the outer fuel plates due to their proximity to the furnace walls. During reactor operation these initial imperfections are then magnified because of the thermal stresses present under these conditions. This effect has been demonstrated in the laboratory as shown in Fig. 2 where the temperature differential $\Delta(T)$ indicates the difference in temperature between the side plate and active fuel region.

Need for a mathematical analysis of fuel plate rippling is dictated by the possible closure of the coolant channels resulting from the distortion of adjacent plates. In itself, rippling would only be serious if the stresses imposed were of sufficient magnitude to cause actual plate failure. However, a more likely and a more potentially serious situation could occur if the deflections induced during reactor operation obstructed the coolant flow through a given channel and lowered the index of thermal margin (DNBR) to the point where film boiling would occur. The high fuel plate temperature which would result in this case only tends to magnify the problem. This results in possible contact of adjacent fuel plates and subsequent:failure of the fuel element at the point of contact causing melting and excessive release of fission products . 


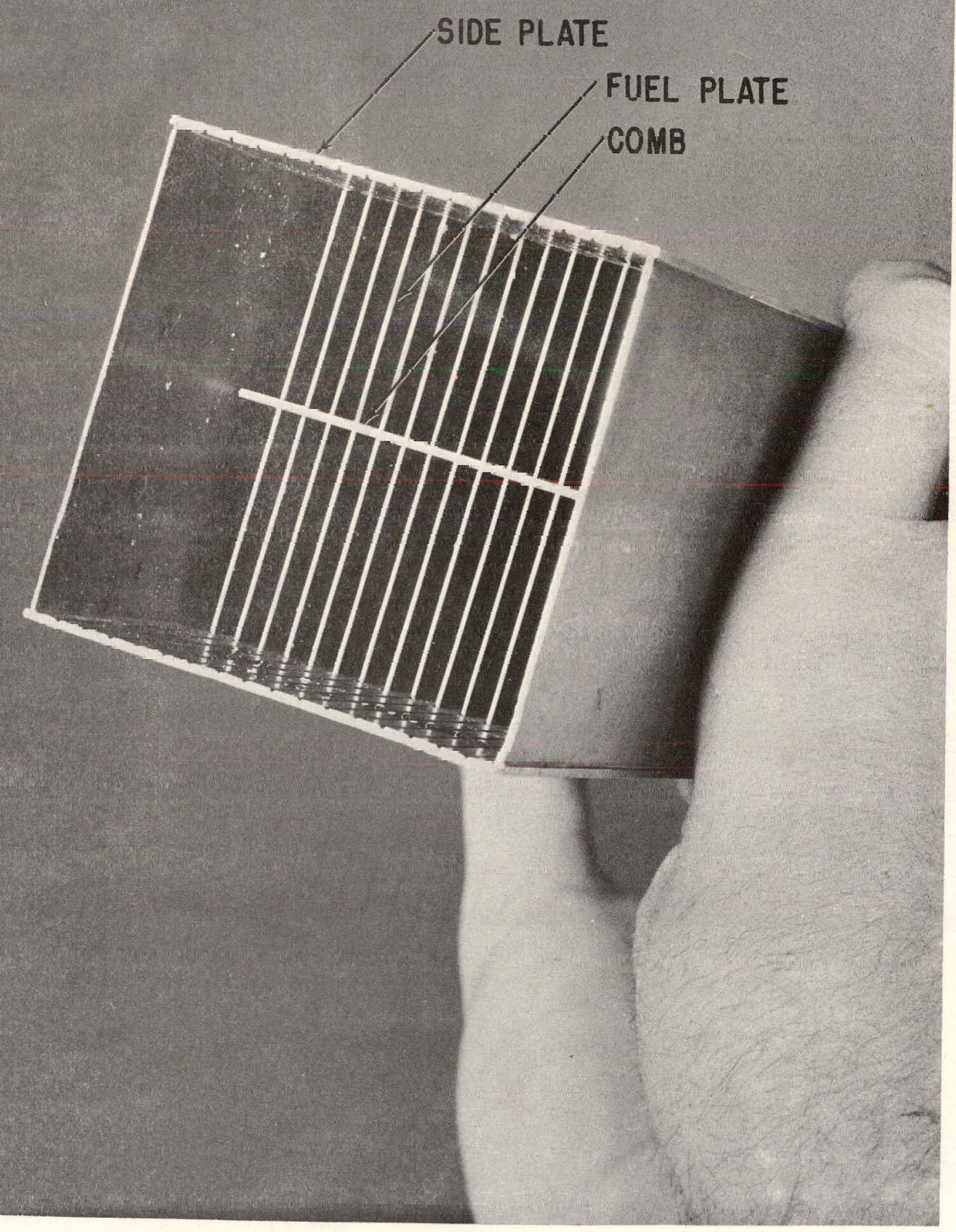

Fig. 1 - Fixed Element with End Box Removed 


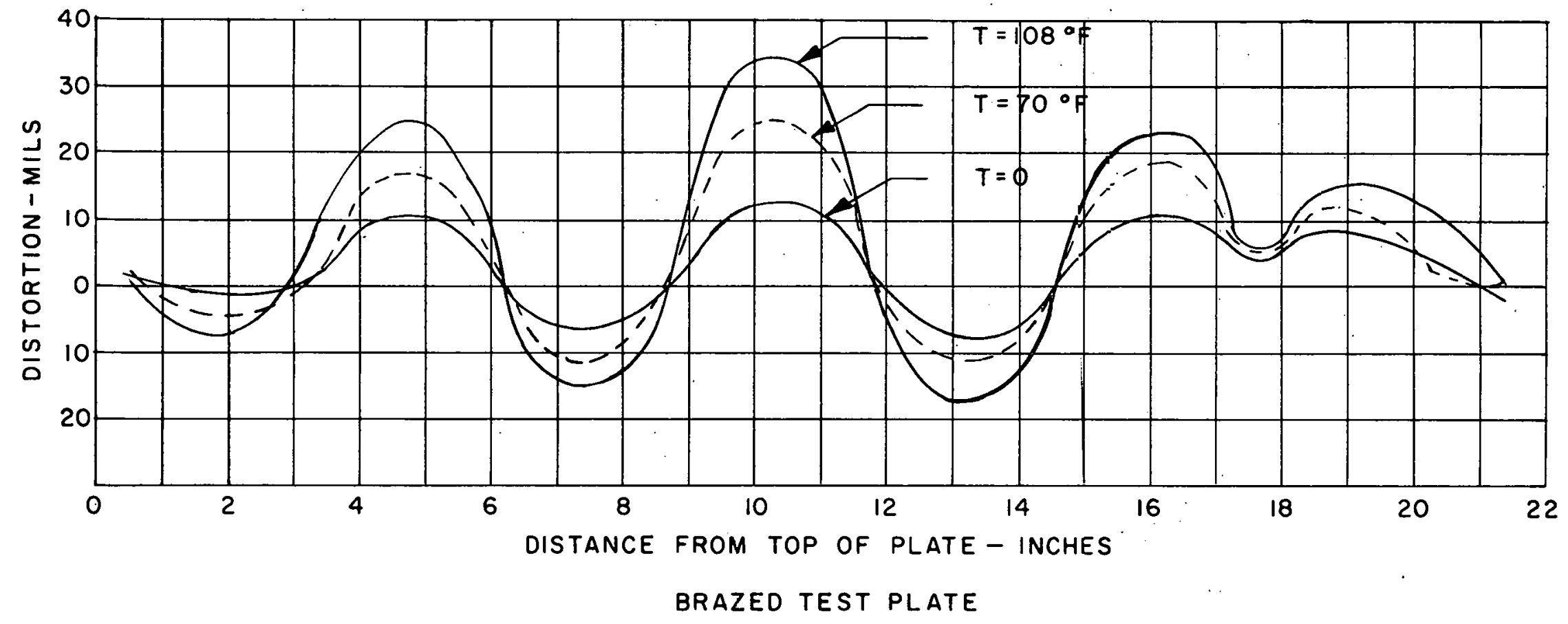

Figure 2 Fuel Plate Distortion Resulting From Thermal Stresses 
In order to estimate the obstruction to coolant flow which may result during operation of the existing and replacement cores, it is necessary to accurately predict the magnitude of the rippling amplitude under actual core operating conditions. This requires, among other things, a knowledge of the initial plate geometry, the physical properties of the material, and an exact understanding of the behavior of the fuel plate (constrained by the side plate) under reactor conditions.

Some tests (see Appendix B) have been made in an effort to relate initial and. final plate geometry under simulated operating conditions. However, as tests, these represent only specific points in a multi-parameter problem. The reliability of extrapolation to other situations depends on the ability to obtain similar results with a mathematical model which incorporates many of these parameters into a single expression relating initial and final conditions of a rippled fuel element.

A mathematical model is proposed which attempts to partially explain rippling phenomena. Considerations in this report are limited to elastic bending and small deflection theory.

The purpose of the mathematical analysis is two-fold:

1. To produce an expression which can be used to check existing experimental data.

2. To provide a reliable tool which can be used as the basis for further investigation into the thermal and hydraulic behavior of a rippled fuel element. 


\subsection{NOMENCLATURE}

$\mathrm{a}=$ length of fuel plate (in.)

$\mathrm{b}=$ width of fuel plate (in.)

$\mathrm{t}=$ thickness of fuel plate (in.)

$\mathrm{L}=$ cross-sectional area of side plate region associated with a fuel plate (in. ${ }^{2}$ )

$y=$ rnordinate distance from one longitudinal edge (in.)

$\mathbf{z}=$ longitudinal coordinate measured from bottom end of core (in.)

$\mathrm{E} \quad=$ modulus of elasticity $\left(\mathrm{lb} / \mathrm{in}_{0}^{2}\right)$

$\alpha=$ coefficient of thermal expansion $\left(\mathrm{F}^{-1}\right)$

$\nu=$ Poison's ratio

$\mathrm{D}=\mathrm{Et} \mathrm{t}^{3} / 12\left(1-\nu^{2}\right)=$ plate rigidity $(\mathrm{lb}-\mathrm{in}$.

$\mathrm{T}=$ temperature excess above bulk coolant temperature $\left({ }^{\circ} \mathrm{F}\right)$

$\sigma_{1}=$ stress in the fuel plate $\left(\mathrm{lb} / \mathrm{in}^{2}\right)$

$\sigma_{2}=$ stress in the side plate (lbs/in 2$)$

$\mathrm{P}=-\mathrm{t} \sigma_{1}=$ stress resultant in fuel plate $(\mathrm{lb} /$ in.)

$\mathrm{Q}=$ loading factor (lb/in.)

$\mathrm{Q}_{\mathrm{Cr}}=$ critical loading factor (lb/in.)

$\mathrm{w}=$ additional deflection of fuel plate (in.)

$\mathrm{w}_{\odot}=$ initial deflection of fuel plate (in.)

A = amplitude of additional deflection (in.)

B = amplitude of initial deflection (in.)

$\mathrm{n}=$ number of half wave lengths 


$$
\begin{aligned}
& U=\text { energy integral (lb-in.) } \\
& \epsilon=\text { longitudinal strain } \\
& \mathrm{d}=\text { channel spacing (in.) }
\end{aligned}
$$




\subsection{RIPPLING ANALYSIS USING SMALL DEFLECTION THEORY}

\subsection{ASSUMPTIONS AND MATHEMATICAL RESULTS}

The investigation of rippling in fuel plates is developed using classical plate theory. Thermal stresses are caused by temperature differences in the plate. Rippling phenomena will be examined.only in terms of symmetric temperature variation across the width of the fuel plate. Plane strain considerations indicate that the hottest part of the plate will be in a state of compresiion.

Temperature variation through the thickness will not contribute to rippling if the distribution is symmetric with respect to the mid-plane of the plate. Temperature variation along the length of the plate is neglected; if this gradient is small, it should have no appreciable effect on rippling.

In this report, the analysis will incorporate small deflection theory. This theory is accurate only for deflections up to the order of the plate thickness. For plates with initial deflections, the theory permits calculating additional. deflections as a function of temperature intensity. For an initially flat plate, the amplitude of deflection. is indeterminate; only the temperature load which causes buckling can be calculated;

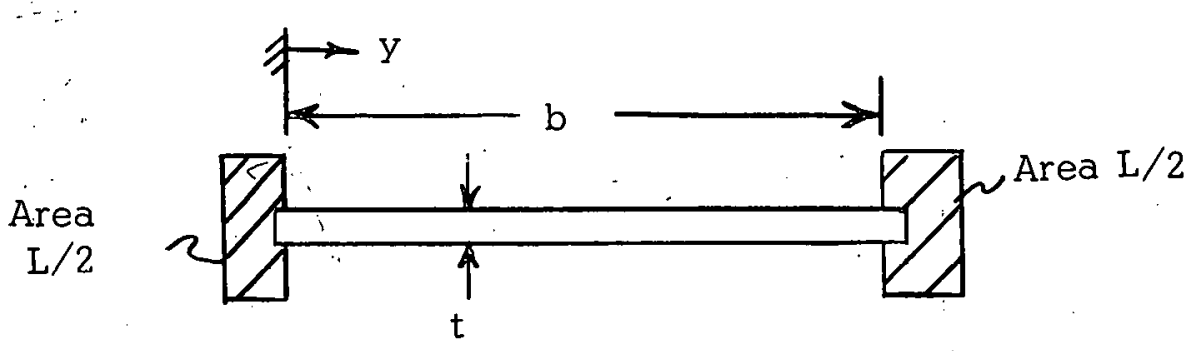

Figure 3. Cross-Section of Fuel Plate with its Associated Element of Side Plate 
A set of fuel plates is fabricated into a box-like fuel element under a pair of side plates. Figure 1 shows a fuel assembly. Figure 3 shows a schematic of the cross-section of a fuel plate and the adjacent side plate region. It is assumed that the side plate region does not bend, has no resistance to twisting and extends elastically. The longitudinal component of strain is assumed constant in both the fuel plate and the side plate.

The plate is assumed to be an elastic, homogeneous, isotropic, medium. It is assumed to be simply supported on all four edges; with respect to the longitudinal edges. This assumption is conservative since the side plates provide some resistance to angular deflection of the plate. The short edges of the plate are free (except for a short region near the inlet comb), thus introducing a slight, optimistic error which is neglected, since the width of the plate is small compared to the length.

The thermal stress distribution is calculated by taking into account the transverse temperature distribution. Plane strain is assumed for the composite plate (i.e., the fuel plate and associated side plate region). It is assumed that the fuel plate and side plate have identical elastic properties. The temperature in the fuel plate is given by a known function, $\mathrm{T}=\mathrm{T}(\mathrm{y})$, symmetric about $y=b / 2$, and in the side plate $T=0$. The area of the side plate portion is $\mathrm{L}$. The stresses in the fuel plate and side plate due to the thermal loading are given respectively by

$$
\begin{aligned}
& \sigma_{1}=E \alpha\left[\frac{t \int_{0}^{b} T d y}{b t+L}-T\right] \\
& \sigma_{2}=\frac{E \alpha t}{b t+L} \int_{0}^{b} T d y
\end{aligned}
$$

Define the loading function as

$$
P=-t \quad \sigma_{1}
$$

and the loading factor

$$
Q=(2 / b) \int_{0}^{b} P \sin ^{2}(\pi y / b) d y
$$

Define the critical loading factor as

$$
\mathrm{Q}_{\mathrm{Cr}}=\pi^{2} \mathrm{D}(\mathrm{a} / \mathrm{m})^{2}\left[(\mathrm{~m} / \mathrm{a})^{2}+(\mathrm{l} / \mathrm{b})^{2}\right]^{2}
$$


Assume that the longitudinal mid-line of the plate deflects into a simple sine curve with $\mathrm{n}$ half-waves and that the deflection across the plate may be represented by a single half-wave. The deflection of the plate is then expressed by

$$
w=A \sin (n \pi z / a) \sin (\pi y / b)
$$

The temperature at which buckling occurs is found when

$$
Q=Q_{C r}
$$

where $Q$ and $Q_{C r}$ are given by equations (4) and (5). Note that the temperature is implicitly incorporated in $Q$ as a consequence of (1) and (3).

If the plate has an initial deflection shape

$$
w_{0}=B \sin (n \pi z / a) \sin (\pi \cdot y / b)
$$

such that the deflection mode is the same as the buckling mode, then the total deflection of the plate is (as shown in Section 3.2).

$$
\frac{A+B}{B}=\frac{1}{1-Q / Q_{C r}}
$$

or

$$
\frac{\mathrm{A}}{\mathrm{B}}=\frac{1}{\mathrm{Q}_{\mathrm{Cr}} / \mathrm{Q}-1}
$$

Table 1 shows a tabulation of $(A+B) / B$ versus $Q / Q_{C r}$ from Equation (9).

\section{TABLE 1}

\section{RIPPLING AMPLITUDES}

$\begin{array}{llcc}Q / Q_{C r} & \frac{(A+B) / B}{1.000} & \frac{Q / Q_{C r}}{0.55} & \frac{(A+B) / B}{2.222} \\ 0 & 1.053 & 0.60 & 2.500 \\ 0.05 & 1.111 & 0.65 & 2.857 \\ 0.10 & 1.176 & 0.70 & 3.333 \\ 0.15 & 1.250 & 0.75 & 4.000 \\ 0.25 & 1.333 & 0.80 & 5.000 \\ 0.30 & 1.429 & 0.85 & 6.667 \\ 0.35 & 1.538 & 0.90 & 10.000 \\ 0.40 & 1.667 & 0.95 & 20.000 \\ 0.45 & 1.818 & 1.00 & \infty \\ 0.50 & 2.000 & & \end{array}$

Note: The temperature-amplitude relation can be found by noting that

$$
\mathrm{T}_{\mathrm{O}}=\mathrm{T}_{\mathrm{O} \text { cr }}\left(\mathrm{Q} / \mathrm{Q}_{\mathrm{Cr}}\right)
$$




\subsection{DERIVATION OF RESULTS FROM SMALL DEFLECTION THEORY}

The deflection equation for a flat plate subjected to no load normal to the plane of the plate and to uniaxial in-plane stress is (1)

$$
w=(-P / D)\left(w_{0} \cdot z z+w_{1} z\right)
$$

where the comma followed by a literal subscript indicates the derivative, in this case, the second. The initial deflection, $w_{O}$, and the compressive stress resultant - P are assumed known. Equation (11) is identical with that for an initially flat plate with in-plane stress resultant, $-\mathrm{P}$ and with loading normal to the plane of the plate $-\mathrm{Pw}_{\mathrm{O}} \mathrm{zz}_{\mathrm{z}}$. The strain energy associated with the deflections of the plate can therefore be written in terms of the energy of the corresponding flat plate. (1)

$$
\begin{aligned}
& U=(1 / 2) \int_{0}^{a} \int_{0}^{b}\left\{-P w, z^{2}+D\left[\left(\nabla^{2} w\right)^{2}-2(1-\nu)(w, z z w, y y-w, z y)^{2}\right]\right. \\
& +2 w P w, z z\} d z d y
\end{aligned}
$$

Of all possible deflections that satisfy the boundary conditions, the one that minimizes this energy expression is the correct solution to Equation (11). The usual procedure for finding an approximate expression for the deflections is to assume a deflection shape in terms of one or more parameters and to minimize the energy in terms of these parameters.

In the present problem, we assume a simply supported plate subject to a thermal stress-resultant distribution

$$
\mathrm{P}=\mathrm{P}(\mathrm{y})
$$

The plate is assumed to have initial deflection

$$
\mathrm{w}_{\mathrm{O}}=\mathrm{B} \sin (\mathrm{n} \pi \mathrm{z} / \mathrm{a}) \sin (\pi \mathrm{y} / \mathrm{b})
$$

The additional deflection due to the thermal stress is assumed to have the same characteristic shape as the initial deflection shape

$$
w=A \sin (n \pi z / a) \sin (\pi y / b)
$$

where the parameter $\mathrm{A}$ is to be chosen to minimize the energy integral, Equation (12) 
Substitution of Equations (13), (14), and (15) into (12) gives

$$
U=\frac{a b}{8}\left(\frac{n \pi}{a}\right)^{2} \quad\left[-\left(A^{2}+2 A B\right) Q+A^{2} Q_{C r}\right]
$$

where

$$
Q=(2 / b) \quad \int_{0}^{b} P \sin ^{2}(\pi y / b) d y
$$

and

$$
Q_{C r}=\pi^{2} D(a / n)^{2}\left[(n / a)^{2}+(1 / b)^{2}\right]^{2}
$$

Setting

$$
\frac{d u}{d A}=0
$$

gives

$$
A=B Q /\left(Q_{C r}-Q\right)
$$

from which Equations (9) and (10) are immediately obtained.

The stress. resultant $P$ is found from thermal stress considerations. The : stress-strain law for a plate subject to a temperature distribution which varies only in one direction may be written

$$
\epsilon=\sigma / E+\alpha T
$$

Let the subscripts 1 and 2 represent the stress in the fuel plate and side plate, respectively. Then

$$
\begin{aligned}
& \sigma_{1}=E(\epsilon-\alpha \mathrm{T}) \\
& \sigma_{2}=\mathrm{E} \epsilon
\end{aligned}
$$

The absence of a temperature term in Equation (23) comes from the assumption: that the side plate temperature is zero. The total force acting on any cross section of the plate must vanish. This is expressed as:

$$
\mathrm{L} \sigma_{2}+\int_{0}^{\mathrm{b}} \sigma_{1} \quad \mathrm{dy}=0
$$


Substituting Equations (22) and (23) and noting that $\epsilon$ is a constant, we may write

$$
\begin{array}{ll} 
& E\left[\int_{0}^{b}(\epsilon-\alpha \mathrm{T}) d y+\mathrm{L} \epsilon=0\right] \\
\cdots & =\frac{\alpha \mathrm{t} \int_{0}^{\mathrm{b}} \mathrm{T} \cdot \mathrm{dy}}{\mathrm{L}+\mathrm{bt}} \\
\mathrm{P} & =-\sigma_{1^{\mathrm{t}}}=\frac{\mathrm{E} \alpha \mathrm{t}}{\mathrm{L}+\mathrm{bt}}\left[(\mathrm{L}+\mathrm{bt}) \mathrm{T}-\mathrm{t} \cdot \int_{0}^{\mathrm{b}} \mathrm{T} d \mathrm{~d}\right]
\end{array}
$$

Equations (20) and (27) provide the formulas necessary for small-deflection analysis. 


\subsection{APPLICATION OF MATHEMATICAL MODEL}

Described in the previous sections are the necessary equations to : mathematically predict the additional deflection of an initially:distorted plate due to the effect of thermal stresses. These equations are summarized below and will be used to show how the characteristic deflection varies with temperature distribution.

\section{1' SUMMARY OF EQUATIONS (Small deflection Theory)}

$$
\begin{aligned}
& \frac{A+B}{B}=\frac{1}{1-Q / Q_{C r}} \\
& Q_{C r}=\pi^{2} D(a / n)^{2}\left[(n / a)^{2}+(1 / b)^{2}\right]^{2}
\end{aligned}
$$

ẉhere

$$
\begin{aligned}
D & =\frac{E t^{3}}{12\left(1-\nu^{2}\right)} \\
Q & =\frac{2}{b} \int_{0}^{b} P \sin ^{2}\left|\left(\frac{\pi y}{b}\right)\right| d y
\end{aligned}
$$

where

$$
P \quad=-t \quad \sigma
$$

and

$$
\sigma_{1}=E \alpha\left[\frac{\mathrm{t} \int_{0}^{\mathrm{b}} \mathrm{T} d \mathrm{~d}}{\mathrm{bt}+\mathrm{L}}-\mathrm{T}\right]
$$

\subsection{CRITICAL LOADING FACTOR}

The critical loading factor, $Q_{C r}$, is mainly a function of plate properties and boundary conditions and will be identical for a given plate for all temperature distributions. Assuming that the ratio $\mathrm{a} / \mathrm{h}$ is approximately equal to $\mathrm{b}$ (simply supported case), the equation for $Q_{\mathrm{Cr}}$ becomes

$$
\mathrm{Q}_{\mathrm{Cr}}=4 \pi^{2} \mathrm{D} / \mathrm{b}^{2}=\pi^{2} \mathrm{E} \mathrm{t}^{3} /\left[3 \mathrm{~b}^{2}\left(1-\left(y^{2}\right)\right]\right.
$$


Typical values for properties

(3) and geometry ${ }^{(4)}$ for Type 1 plates at about $400^{\circ} \mathrm{F}$ to $600^{\circ} \mathrm{F}$ are shown below:
$\mathrm{a}=23 \pm .0156 \mathrm{in}$.
$\mathrm{b}=2.778 \pm .002 \mathrm{in}:$
$t=0.030 \pm .001 \mathrm{in.}$
$\mathrm{L}=0.016 \mathrm{in.}^{2}$
$\mathrm{E}=25 \times 10^{6} \mathrm{psi}$
$\alpha=9.6 \times 10^{-6}$ in $/$ in ${ }^{\circ} \mathrm{F}$
$\nu \quad=0.3$

the following values are obtained from the previous equations

$$
\begin{aligned}
& D=\frac{25 \times 10^{6}\left(\mathrm{lb} / \mathrm{in}^{2}\right)(.029 \mathrm{in})^{3}}{12\left(1-0.3^{2}\right)}=55.84 \mathrm{in}-1 \mathrm{~b} \\
& Q_{\mathrm{Cr}}=\frac{(4) \pi^{2} 55.84 \mathrm{in}-\mathrm{lb}}{(2.78 \mathrm{in})^{2}}=285 \mathrm{lb}-\text { in }
\end{aligned}
$$

\subsection{TEMPERATURE INDUCED LOADS}

Determination of the temperature induced load (Q) is made by solving the appropriate equations for a given temperature distribution. For example, consider the temperature distributions shown on the following figure:

$\underline{\text { UNIFORM }}$

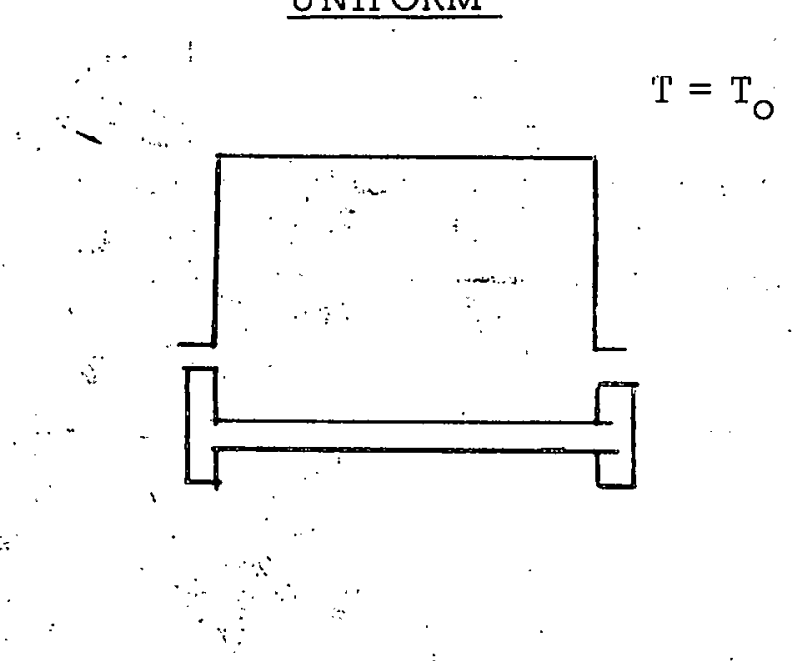

SINUSOIDAL

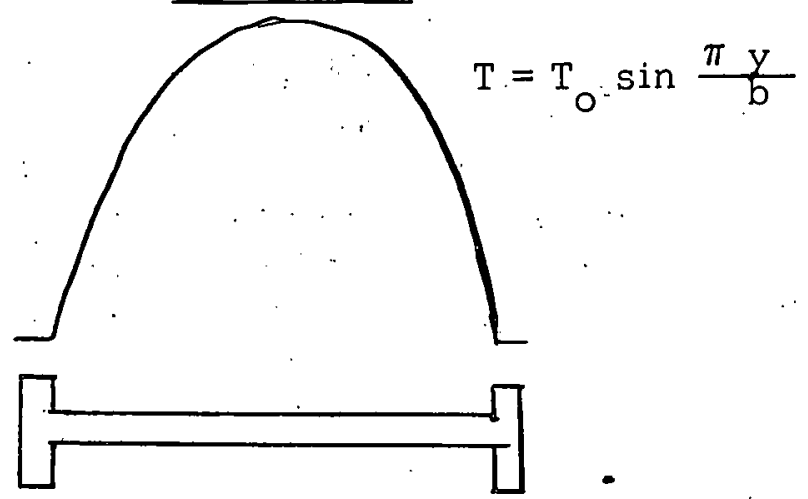

Figure 4. Temperature Distributions Used in Comparison Study 
The stress along the plate for the two cases is found from

$$
\sigma_{1}=E \alpha\left[\frac{\int_{O}^{\mathrm{t}} \mathrm{T} d y}{\mathrm{bt}+\mathrm{L}}-\mathrm{T}\right]
$$

which becomes for the uniform case

$$
\sigma_{1}=-E \alpha T_{0} \frac{L}{t b+L}
$$

and for the sinusoidal distribution

$$
\sigma_{1}=-E \alpha T_{0}\left[\frac{-2 b t}{\pi(t b+L)}+\sin \frac{\pi y}{b}\right]
$$

The resulting loading function $(P)$ is

$$
\mathrm{P}=\mathrm{E} \alpha \mathrm{T}_{\odot}\left[\frac{\mathrm{Lt}}{\mathrm{tb}+\mathrm{L}}\right] \text { for the uniform case }
$$

and

$$
\mathrm{P}=\mathrm{E} \mathrm{T}_{\mathrm{o}} \alpha\left[\mathrm{t} \cdot \sin \left(\frac{\pi \mathrm{y}}{\mathrm{b}}\right)-\frac{2 \cdot \mathrm{bt} \mathrm{t}^{2}}{(\mathrm{tb}+\mathrm{L})}\right]
$$

for the sinusoidal case.

Substitution of these values into the expression for $Q$

$$
\mathrm{Q}=2 / \mathrm{b} \int_{0}^{\mathrm{b}} \mathrm{P} \sin ^{2}(\pi \mathrm{y} / \mathrm{b}) \mathrm{dy}
$$

and integrating with respect to $y$, we have for the uniform distribution

$$
\begin{aligned}
& Q=2 / b \int_{0}^{b}\left[E \alpha T_{0}\left(\frac{L t}{t b+L}\right)\right] \sin ^{2}\left(\frac{\pi}{b}\right) d y \\
& Q=E \alpha T_{0} \frac{L t}{t b+L}
\end{aligned}
$$

Likewise: for the sinusoidal distribution, we: have

$$
\begin{aligned}
& \mathrm{Q}=\frac{2}{\mathrm{~b}} \int_{0}^{\mathrm{b}} \mathrm{E} \alpha \mathrm{T}_{0}\left[\mathrm{t} \sin \left(\frac{\pi \mathrm{y}}{\mathrm{b}}\right)-\frac{2 \mathrm{bt}^{2}}{\mathrm{tb}+\mathrm{L}}\right] \sin ^{2}\left(\frac{\pi \mathrm{y}}{\mathrm{b}}\right) \mathrm{dy} \\
& \mathrm{Q}=\frac{2 \mathrm{E}}{\pi} \alpha_{0} \mathrm{~T}_{0}\left[\frac{4 \mathrm{t}}{3}-\frac{\mathrm{bt}^{2}}{(\mathrm{tb}+\mathrm{L})}\right]
\end{aligned}
$$


This can also be related to the average temperature $\overline{(T)}$ by integration of the temperature function across the plate with the result

$$
Q=E \dot{\alpha} \bar{T}\left[\frac{4 t}{3}-\frac{b t^{2}}{t b+L}\right]
$$

Using the geometry and physical properties which were previously given, the value of $Q$ for the two cases becomes

$$
\begin{aligned}
& \text { (Uniform) } \quad Q=1.152 \mathrm{~T}_{\mathrm{O}} \\
& \text { (Sinusoidal) } Q \doteq 2.215 \mathrm{~T}_{\mathrm{O}} \\
& \text { and } \quad Q=3.478 \overline{\mathrm{T}}
\end{aligned}
$$

Since "Critical" buckling will occur when $Q$ is equal to $Q_{C r}$ the critical temperature can be found by equating these terms.

$$
\text { (Uniform) } \begin{aligned}
\mathrm{Q} & =1.152 \mathrm{~T}_{\mathrm{o}} \\
\mathrm{Q}_{\mathrm{Cr}} & =285 \mathrm{lb} / \mathrm{in} . \\
\mathrm{T}_{\mathrm{OCr}} & =247.4^{\circ} \mathrm{F} \\
\text { (Sinusoidal) } \mathrm{Q} & =2.215 \mathrm{~T}_{\mathrm{O}} \\
\mathrm{T}_{\mathrm{OCr}} & =128.7^{\circ} \mathrm{F} \text { or } \overline{\mathrm{T}}_{\mathrm{Cr}}=81.9^{\circ} \mathrm{F}
\end{aligned}
$$

The reason for the lower critical value for the sinusoidal temperat ure distribution can be seen by numerically evaluating the stress in the plate.

For the uniform.temperature distribution

$$
\begin{aligned}
& \sigma_{1}=-\mathrm{E} \alpha \mathrm{T}_{0}\left[\frac{\mathrm{L}}{\mathrm{tb}+\mathrm{L}}\right] \\
& \sigma_{1}=-39.75 \mathrm{~T}_{\mathrm{O}}
\end{aligned}
$$

which at the critical temperature $\left(247.4^{\circ} \mathrm{F}\right)$ is

$$
{ }^{\sigma} \text { Crit }=-9,834 \mathrm{psi}
$$

Likewise for the sinusoidal distribution

$$
\begin{aligned}
& \sigma_{1}=-\mathrm{E} \alpha \mathrm{T}_{0}\left[\sin \left(\frac{\pi \cdot \mathrm{y}}{\mathrm{b}}\right)-\frac{2 \mathrm{bt}}{(\mathrm{tb}+\mathrm{L})}\right] \\
& \sigma_{1}=-240 \mathrm{~T}_{0}\left[\sin \frac{\pi \mathrm{y}}{\mathrm{b}}-.5316\right]
\end{aligned}
$$


the maximum compressive stress at the center of the plate is then

$$
\sigma_{\max }=-112.4 \mathrm{~T}_{\mathrm{O}}
$$

and the critical stress at the critical temperature is

$$
\sigma_{\mathrm{cr}}=-14,468 \mathrm{psi}
$$

The stress distributions. for the two cases are shown on Fig. 5 .

Although the "effective buckling span" (that portion of the plate in compression) is smaller for the sinusoidal temperature distribution, the higher compressive force in this region more than compensates for this difference in span and results in a lower buckling temperature than for the uniform case.

\subsection{AMPLIFICATION FACTOR}

The amplification factor on plate deflection, $(A+B) / B$, which is defined as the ratio of the total to the initial amplitude of the ripple, is shown as a function of peak temperature on Fig. 6. Using the value of $108^{\circ} \mathrm{F}$ (5) as the maximum temperature differential in the SM-1A Core $I$, the amplification factor can be determined from Equation ( 9 ).

$$
\frac{A+B}{B}=\frac{1}{1-Q / Q_{C r}}
$$

which for the uniform distribution is

$$
\frac{A+B}{B}=\frac{1}{1-(1.152 \mathrm{~T}) / 285}=1.77
$$

and for the sinusoidal temperature distribution

$$
\frac{A+B}{B}=\frac{1}{1-(2.215 \mathrm{~T} / 285)}=6.23
$$

Since the actual SM-IA temperature distribution is somewhere between the two cases presented here, the value of 2.64. (see Appendix B) determined from experimental results is not unreasonable:

To apply this mathematical model to the exact form of the SM-1A temperature profile requires that the distribution be represented in a mathematical form. 


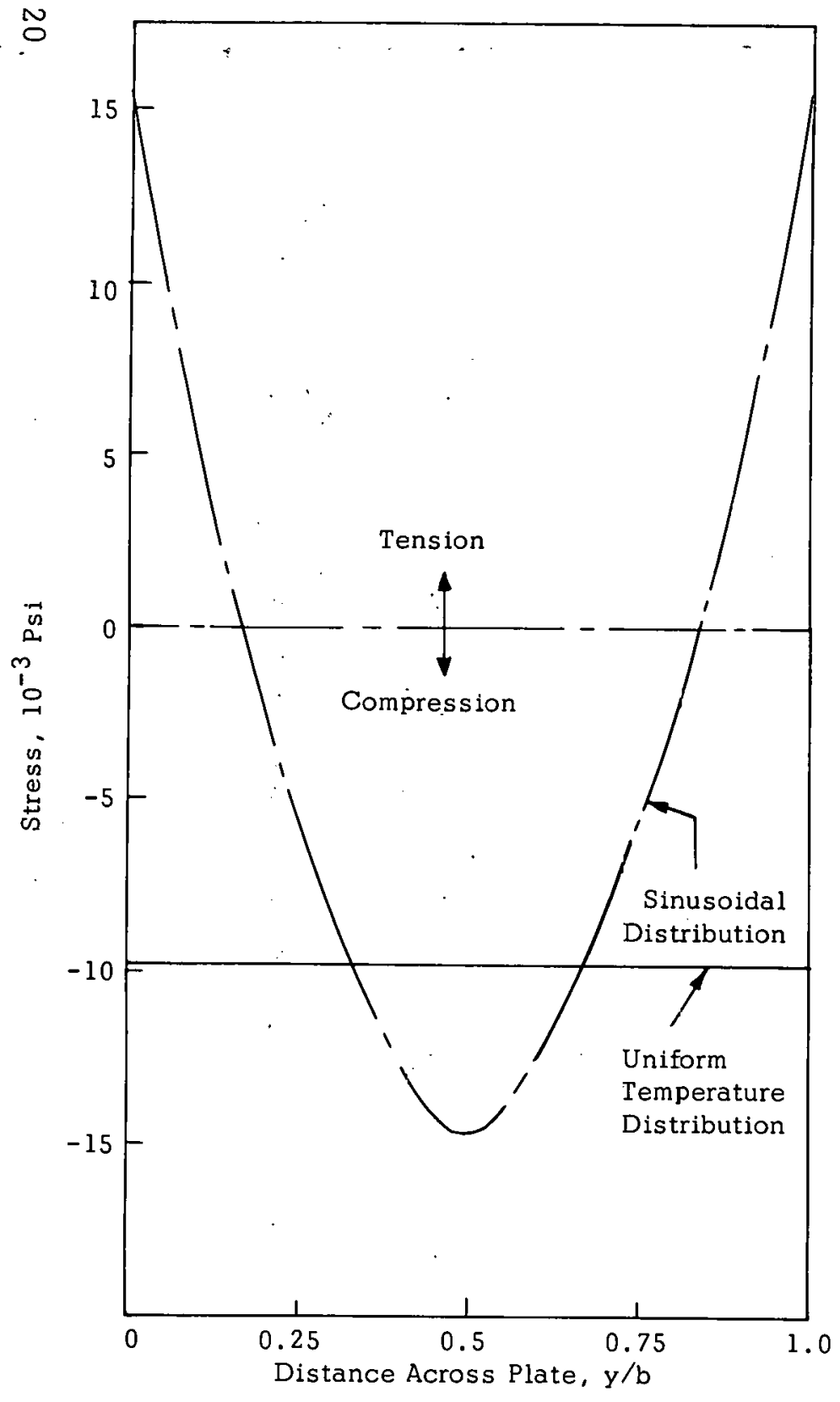

Figure 5. Comparison of Stress Distributions Induced By Thermal Loading

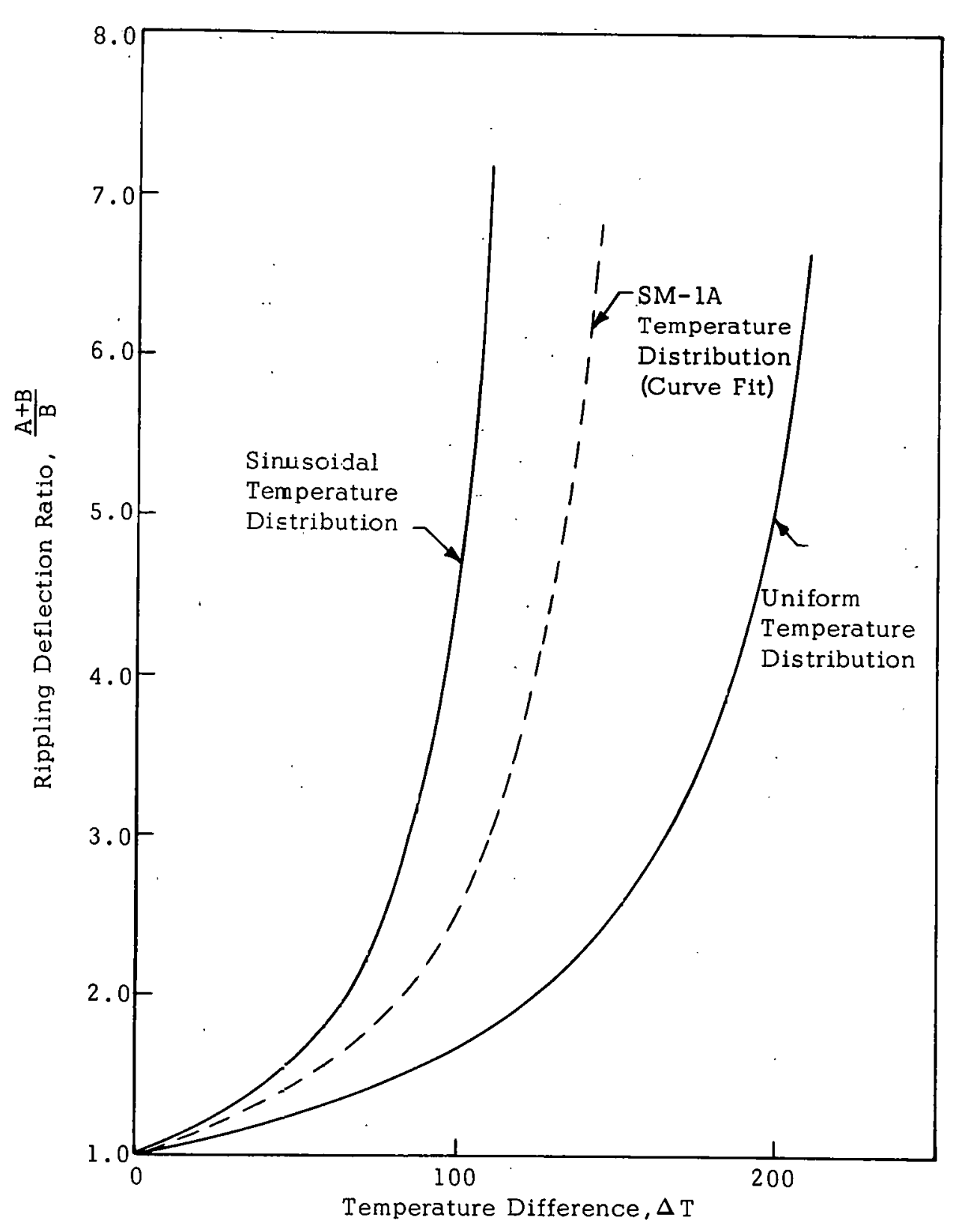

Figure $\epsilon$. Comparison of Deflection Ratios Caused By Various Temperature Distributions 


\subsection{SM-1A TEMPERATURE. DISTRIBUTION AND COMPARISON OF TEST RESULTS}

Figure 7 shows a "hot spot" temperature profile for the SM-1A type cores. The single fuel plate test ${ }^{(5)}$ was designed. to approximate this temperature distribution. To apply the mathematical model to this case it is first necessary to express this curve in a functional form.

Let us assume that the temperature distribution can be expressed as a cosine series:

$$
T=T_{0} \Sigma_{i=0}^{N} A_{i} \cos \left(\frac{2 \pi}{b}\right)
$$

or $\mathrm{T}=\mathrm{T}_{\circ}\left[\mathrm{A}_{\mathrm{O}}+\mathrm{A} \cos \frac{2 \pi \mathrm{y}}{\mathrm{b}}+\mathrm{A}_{2} \cos \frac{4 \pi \mathrm{y}}{\mathrm{b}}+\ldots+\mathrm{A}_{\mathrm{N}} \cos \left(\frac{2 \pi N y}{\mathrm{~b}}\right)\right]$

where

$\mathrm{T}_{\mathrm{O}}$ and $\mathrm{y}=0$ are as shown on Fig. 7 :

The stress function can be found from Equation (1),

$$
\sigma_{1}=E \alpha\left[\frac{t}{b t+L} \quad \int_{0}^{b} T d y-T\right]
$$

Integrating the temperature function by parts gives

$$
\begin{aligned}
& \text { for } i=0) \quad \int_{0}^{b} A_{0} d y=A_{0} b \\
& \begin{array}{ccc}
i=1) & \int_{0}^{b} A_{1} \cos \left(\frac{2 \pi}{b}\right)_{1} d y=0 \\
1 & 1 & 1 \\
1 & 1 & 1
\end{array} \\
& \mathrm{i}=\mathrm{N}) \int_{0}^{\mathrm{b}} \quad \mathrm{A}_{\mathrm{N}} \cos \frac{2 \mathrm{Ny}}{\mathrm{b}^{b}}=0
\end{aligned}
$$

so that

$$
\sigma_{1}=E \alpha\left[\frac{\mathrm{tb} A_{0} T_{0}}{(b t+L)}-T\right]
$$




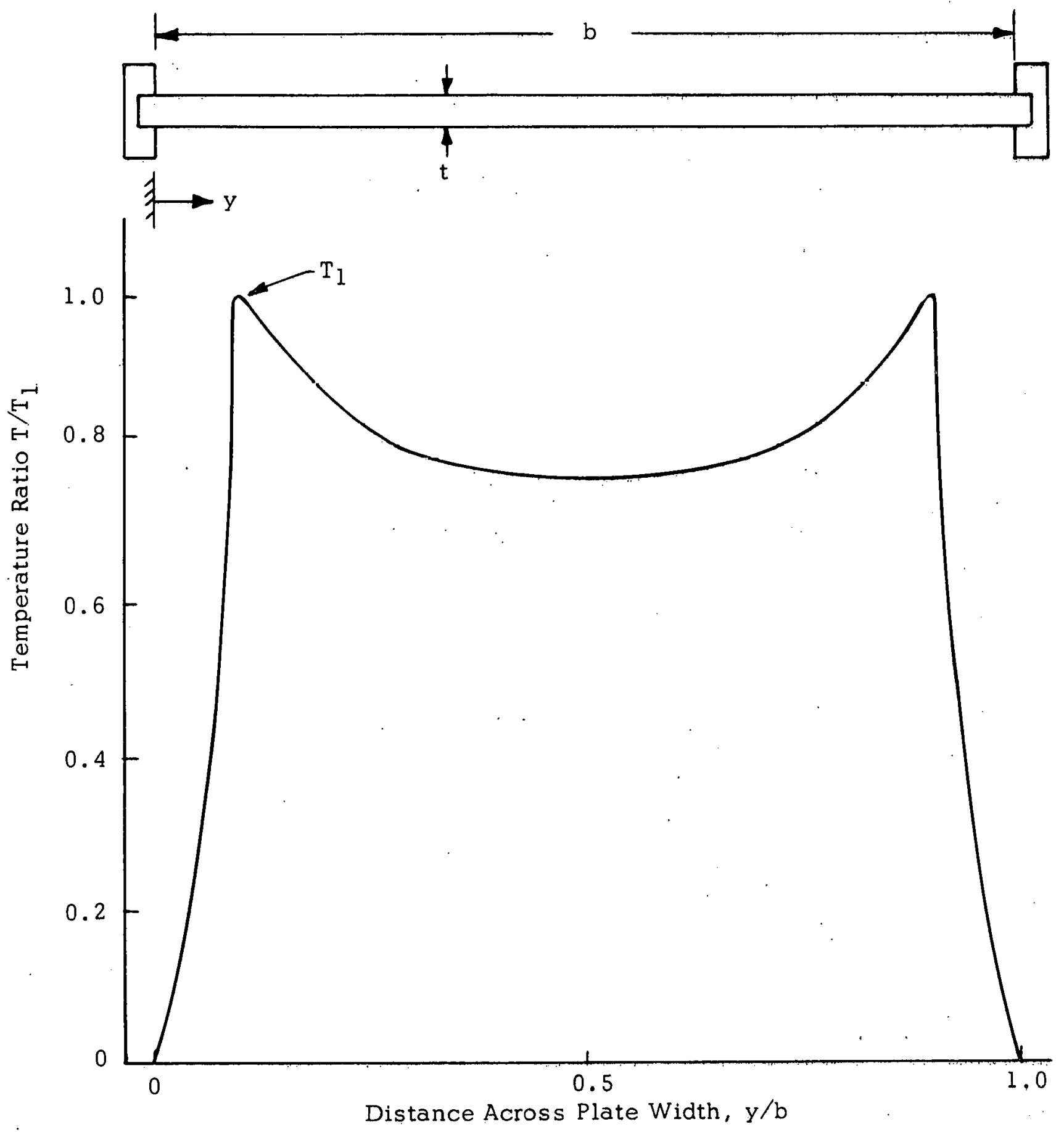

Figure 7. Typical SM-1A Temperature Distribution 
The loading function can then be expressed by

$$
P=E \alpha t\left[T-\frac{t b A_{o} T_{o}}{b t+L}\right]
$$

which ean be substltuted in equation (4) to solve for $\bar{Q}$

$$
Q=\frac{2 E \alpha t}{b} \int_{0}^{b}\left[T-\frac{t b A_{O} T_{O}}{b t+L}\right] \sin ^{2}\left(\frac{2 \pi y}{b}\right) d y
$$

Substituting for $T$ from Equation (42) and again integrating by parts

$$
\begin{aligned}
& \text { for } i=0) \int_{0}^{b} \quad A_{0} \sin ^{2}\left(\frac{2 \pi}{b}\right) d y=A_{0} \quad b / 2 \\
& i=1) \int_{0}^{b} A \cos \left(\frac{2 \pi y}{b}\right) \sin ^{2}\left(\frac{2 \pi y}{b}\right) d y=A_{1} b / 2 \\
& i=2) \int_{0}^{b} \quad A_{2} \cos :\left(\frac{4 \pi y}{b}\right) \sin ^{2}\left(\frac{2 \pi y}{p}\right) \quad d y=0 \\
& \begin{array}{ll}
1 & 1 \\
1 & 1 \\
1 & 1
\end{array} \\
& i=\dot{\mathrm{N}}) \int_{0}^{\hat{b}} \ddot{A}_{\hat{N}} \cos \left(\frac{2 \pi N y}{b}\right) \sin ^{2}\left(\frac{2 \pi y}{b}\right) d y=0
\end{aligned}
$$

ând the lâs ŝt têrm becómèn

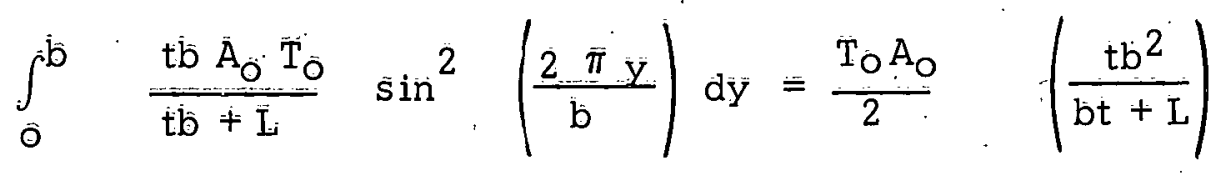

Becâuse of the orthogonality of the function the integrals are equal to zero

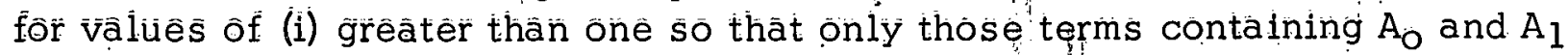
âre ố signifificance in the evàluation of the integral. 
Substituting the individual factors into the expression for $Q$, we have

$$
Q=\frac{2 E \alpha t T_{0}}{b} \cdot\left[A_{0} b / 2-A_{l} b / 2-\frac{A_{0}}{2}\left(\frac{t b^{2}}{b t+L}\right)\right]
$$

or

$$
Q=E \alpha \mathrm{T}_{0}\left[\mathrm{~A}_{0}\left(1-\frac{\mathrm{tb}}{\mathrm{bt}+\mathrm{L}}\right)-\mathrm{A}_{1}\right]
$$

An IBM-6.50 digital code (6) was programmed to approximate temperature distribution with a 10th order cosine fit. Results of the calculation for the SM-1A profile indicated that the slope changes associated with this distribution were too sharp even for a loth order equation and may require several more terms in order to get the exact fit. However, since only the coefficients $A_{0}$ and $A_{1}$ are really significant in the calculation of the thermal load, it was felt that the irregularities in the equation would have little effect on the deflection characteristics of the plate. Coefficients obtained by this method were

$$
\begin{aligned}
& A_{0}=. .6915 \\
& A_{1}=-.1346 \\
& A_{2}=1.2044 \\
& A_{3}=-5.6302 \\
& A_{4}=7.9580 \\
& A_{5}=-4.7530 \\
& A_{6}=-3.2615 \\
& A_{7}=8.0067 \\
& A_{8}=-6.2153 \\
& A_{9}=2.1341
\end{aligned}
$$

Using the values of $A_{0}$ and $A_{1}$, and the dimensions previously given, the thermal load is found to be

$$
\mathrm{Q}:=1.733 \mathrm{~T}_{0} \mathrm{lb} / \mathrm{in} \mathrm{O}^{\circ} \mathrm{F}
$$



so that

As before, the critical value of $T_{1}$ can be found by equating $Q$ and $Q_{C r}$

$$
\text { Critical } \mathrm{T}_{\mathrm{O}}=\frac{285}{1.733}=164.5^{\circ} \mathrm{F}
$$

As expected, this value falls between the critical temperatures calculated for the uniform and sinusoidal distribution.

The amplification factor at $\mathrm{T}_{\mathrm{O}}$ equal to $108^{\circ} \mathrm{F}$ is

$$
\frac{A+B}{B}=\frac{1}{1-\frac{(1.733)(108)}{285}}=2.91
$$

and is therefore very close to the 2.64 value obtained from experimental results (Appendix:B).

At a temperature difference of $80^{\circ} \mathrm{F}$, the amplification factor is

$$
\frac{A+B}{B}=\frac{1}{1-\frac{(80)(1.733)}{285}}=1.95
$$

which is again close to the 2.22 value calculated from experimental results.

Figure 8 is a comparison of the amplification factor found from experiments and the value obtained using the analytic: method described here for the SM- $1 \mathrm{~A}$ temperature distribution. Around the point of interest $\left(80-100^{\circ} \mathrm{F}\right)$ the two curves agree within $\pm 10 \%$. Due to the asymptotic behavior of the small deflection theory, the analytic. results become very conservative as the temperature difference approaches the critical value $\left(164.5^{\circ} \mathrm{F}\right)$. At lower temperatures $\left(<75^{\circ} \mathrm{F}\right)$, the experimental data appear to be more conservative.

It may, therefore, be assumed that the analytical solution is reasonably. valid at SM-1A operating conditions and can be used with a degree of confidence in this range. 


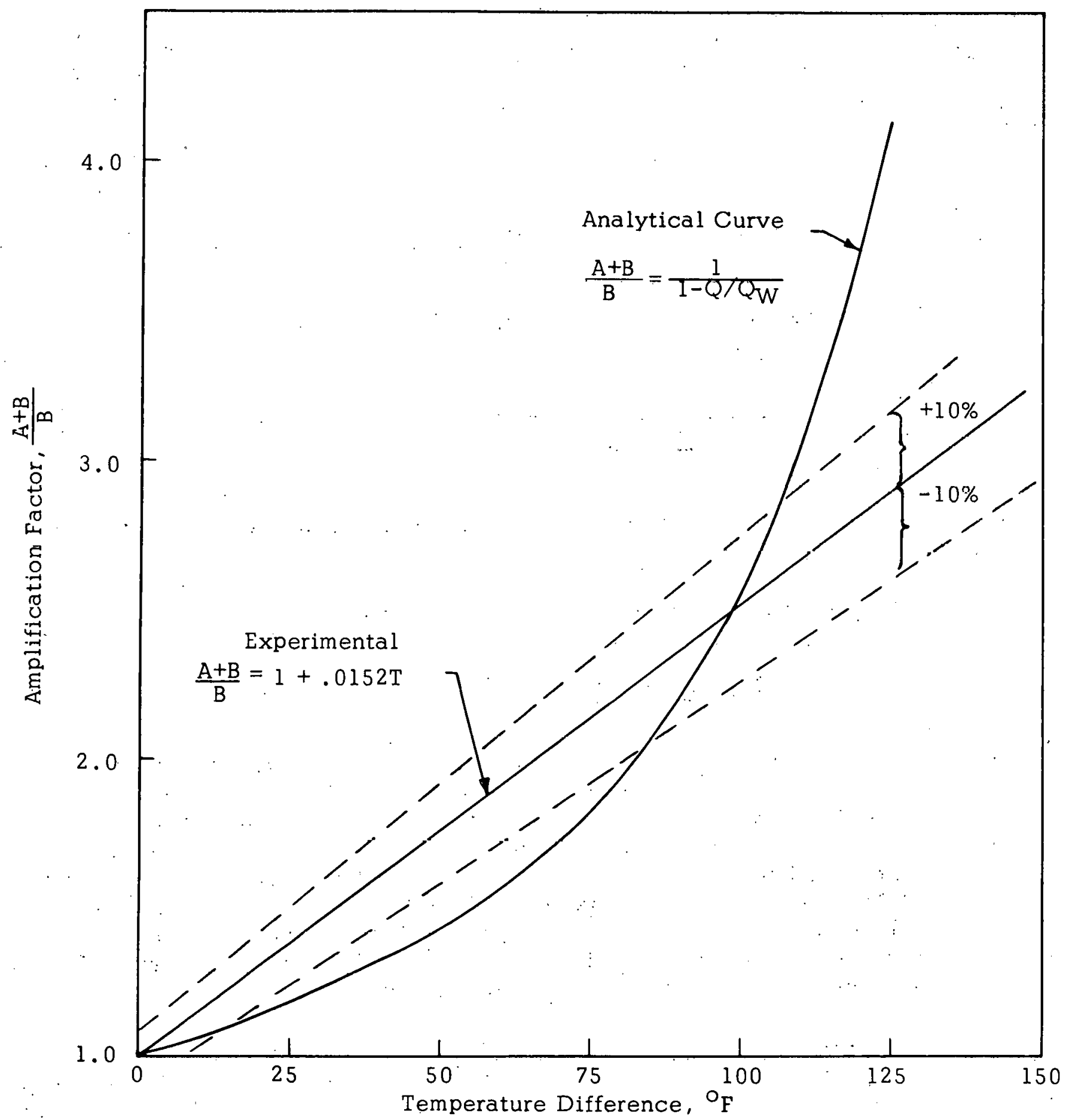

Figure 8. Comparison of Analytic and Experimental Ripple Amplification Factor 


\section{0 - FUTURE:WORK}

\subsection{CHARACTERISTICS OF LARGE DEFLECTION THEORY}

Greater accuracy for calculating rippling amplitudes is possible using large deflection theory. As pointed out earlier, small deflection theory is accurate only for amplitudes of the order of magnitude of the plate thickness: As the loads approach buckling loads, the error of small deflection theory becomes progressively worse. The main difficulty is that small deflection theory ignores the stretching of the middle plane of the plate.

Large deflection theory accounts for the finite changes of dimension and for the restraint of the stresses associated with stretching of the plate. It is necessary in large deflection theory to examine a pair of coupled non-linear differential equations and associated boundary conditions.

The application of large deflection theory of plates to the problem of plate rippling requires consideration of temperature distribution. Initial. flat plates are treated by the Von Karman equations For plates with inttial curvature the Marguerre equations are used. Coan $(7)$ and Yamaki (8) have examined the Marguerre equations in some detall for edge loading. Boley and Weiner (2) have investigated simple temperature distributions in flat plates. A combination of the temperature effects and initial curvature effect is needed for the rippling problem. The Marguerre equations then will be

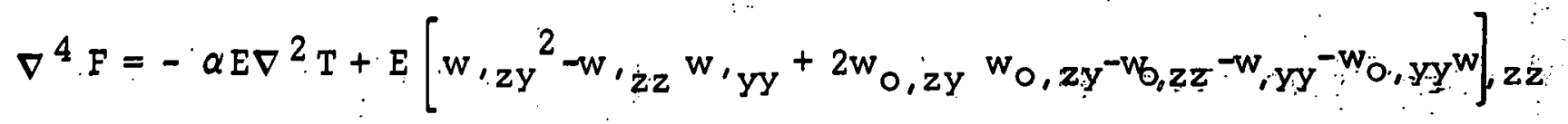

and

$$
\nabla^{4}, w=(t / D)\left[F_{1 y y}\left(w+w_{0}\right), z z+F_{, z z}\left(w+w_{0}\right), y y-2 F, z y\left(w+w_{0}\right), z y\right]
$$

$F$ is the Airy stress function, related to the stresses by

$$
\begin{aligned}
& \sigma_{, z z}=\cdot F, y y \\
& \sigma_{y y}=F, z z \\
& \sigma_{y z}=-F, y z
\end{aligned}
$$

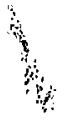

Suitable boundary conditions must be chosen to fit a given problem. In addition to the conditions on $w$, which are identical to those considered in. small deflection analysis, stresses or displacements in the plane of the plate must be prescribed. 
Several approximate techniques are available for solutions of these equations. The two most important of these are successive approximations and matching coefficients. In the first, the equations are linearized by a suitable approximation of $\mathrm{w}$. The first equation is solved and the approximate. value of $F$ and $W$ are substituted into the second equation which is then solved. This solution, according to Boley and Weiner is quite accurate. In the second method, $F$ and $w$ are represented by trigonometric series whose coefficients are found to satisfy the equations and boundary conditions.

The detailed: solution of the Marguerre equations is tedious in either case but is required for an accurate solution if deflections or thermal loads exceed the limitations of small deflection theory. Since it appears (Fig.8) that the present tests are approaching the limit of small deflection theory, more advanced testing $\left(\mathrm{T}>125^{\circ} \mathrm{F}\right)$ will require the large deflection analysis. 
1. Timoshenko S. and Woinow sky-Krieger, "Theory of Plates and Shells", Second Edition, McGraw-Hill, 1959.

2. Boley, Bruno A. and Weiner Jerome H., "Theory of Thermal Stresses". John Wiley, 1960.

3. Letter: Mr. G.W. Cunningham, Battelle Memorial Institute to Mr. J.Gallagher, Alco Products, March 12, 1962, Subj: Mechanical and Physical Properties of $\mathrm{UO}_{2}$ Stainless Steel Dispersions.

4. Gallagher, J.G., et al, "Nuclear Technology Data for $S M-1, S M-1 A$, PM-2A, SM-2", AP Note-357; Alco Products, Inc., June 12, 1961.

5. Gebhardt, F.G. ,"Thermal Stress Testing of Type I Single Fuel Plates," APAE Memo-317, to be:issued June 1962 .

6. Moak, R., "COFIT, An IBM 650 Program for Approximating Irregular Shaped Curves with a l0th Order Cosine Fit," unpublished.

7. Coan, J.M., "Large Deflection Theory for Plates with Small Initial Curvature Loaded in Edge Compression," J. Appl. Mech. 18, June 1951, pp. 143-151:

8. Yamaki, Noburo, "Postbuckling Behavior of Rectangular Plates with Small.Initial Curvature Loaded in Edge Compression," J. Appl. Mech., 26, Sept. 1959, pp. 407-414. 


\section{APPENDIX A- BIBLIOGRAPHY}

The authors of this report have examined a large body of pertinent literature in the course of the present investigation. "For the investigator who wishes. to pursue the field in greater detail, the following reports may be of interest:

H.M. Berger, "A New Approach to the Analysis of Large Deflections of Plates," J。Appl。Mech., 22 , (Dec.55), pp. 465-472

Sara R. Boley, "A Procedure for the Approximate Analysis of BuckledPlates," J。Aero.Sci., 22 (May 55), pp. 3.37-3.3.9

T. Buchwald and R. Tiffen, "Boundary-Value Problems of Simply Supported Elastic Plates," Q.J. Mech.Appl. Math., (Dec.56), pp.489-498

Bernard Budiansky and Pai.C.Hu, "The Lagrangian Multiplier Method of Finding Upper and Lower Limits to Critical Stresses of Clamped Plates," NACA Report 848 (1946)

J.M.Coan, "Large-Deflection Theory for Plates with Small Initial Curvature Loaded in Edge Compression," J. Appl. Mech. 18, (June 51), pp. 143-151

H.D. Conway and A.W. Leissa, "A Method for Investigating Certain Eigenvalue Problems of the Buckling and Vibration of Plates" J. Appl. Mech. , 27 (Sept。60) pp. 557-558

H.L. Cox, "The Buckling of a Flat Rectangular Plate-under Axial Compression and its behavior after Buckling", Aero. Res. Counc., London, R \& M No.2041, (May 1945)

H.L. Cox, "The Buckling of a Flat Rectangular Plate under Axial Compression and its Behavior after Buckling II -Conditions for Permanent Buckles," Aero Res. Counc., London, R \&:M 2175, (Oct.1945)

H.L. Cox, "The Buckling of Thin Plates in Compression," Tech. Report of Aero. Res. Comm。(1933-4) R \&:M 1554, pp.443-463

H. Deresiewicz, "Solution of the Equations of Thermoelasticity," Proc. 3rd U.S. Nat'1. Cong. Appl。Mech (1958), pp. 287-291

B.E. Gatewood, "Thermal Stresses in Moderately Thick. Elastic Plates, J. Appl. Mech, 26, (Sept.59), pp.432-436

George Gerard and Herbert Becker, "Handbook of Structural Stability," Parts I - VI" NACA TN 3781-3786 (1957) 
A. I. Goldenveizer, "On Reissner's Theory of the Bending of Plates," NASA TT F-27, (May 1960)

Myron L. Gossard, Paul Seide and William M. Roberts, "Thermal Buckling of Plates," NACA TN 2771 (August 1952)

A. E. Green, "The Eleastic Equilibrium of Isotropic Plates and Cylinders," Froc. Roy.Soc.Lond., Ser A, 195, (Feb. 49) pp. 533-552

D. S. Griffin, "Inelastic Deflection and Buckling of Fuel Plates Due to Fluid Velocity: and Compressive Edge Loads," WAPD-TM-285 (Sept. 1961)

G. H. Handelman and W. Prager, "Plastic Buckling of a Rectangular Plate under Edge Thrusts," NACA Report 946 (1949)

George J. Heimerl and William M. Roberts, "Determination of Plate Compressive Strengths at Elevated Temperatures," NACA Report 960 (1950)

Richard R。Heldenfels and William M. Roberts, "Experimental and Theoretical Determination of Thermal Stresses in a Flat Plate," NACA TN 2769 (Aug。1952)

Yoichi Higashi, "Bending of Thin. Rectangular Plates with Any Boundary Conditions," Mem. Fac. Technol. Tokyo Univ. No.6 (1956), pp.45-17

N。 J。 Hoff, "Buckling and Stability," J. Roy. Soc. Aero. 58, (Jan. 1954) pp. $3-52$

N. J. Hoff, "Buckling at High Temperature," J. Roy. Aero. Soc. , 61, (Nov。 57) pp. 756-774

N.J. Hoff, "Thermal Buckling of Supersonic Wing Panels,." J. Aero. Sci., 23. (Nov。 56), pp, 1019-1028, 1050

John C.Houbolt and Elbridge Z. Stowell, "Critical Stress of Plate Columns," NACA TN 2163 (Aug。1950)

Pai C.Hu and Eugene E. Lundquist, "Effect of Small Deviations from Flatness on Effective Width and Buckling of Plates in Compression," NACA $\operatorname{TN} 112.4,(1946)$

P.C. FIuang, C。J. Van Der Maas, "Combined Effects of Axial Load, Thermal Stress, and Creep in Flat Plates," WADC TR 57-442 (March 1958) (AD 22680.7)

P.C. Huang, C.J. Van Der Maas, "Combined Effects of Axial Load, Thermal Stress, and Creep in Flat. Plates; Large-Deflection Analysis of Buckled Plates under Thermal Effects," WADC TR 57-442, Suppl. 1, (Feb. 1959) (AD 229 788) 
A.A. Ilyushin, "The Elasto-Plastic Stability of Plates," NACA TM 1188 , (Dec.1947)

A.A. Ilyushin, "Stability of Plates and Shells beyond the Proportional Limit," NACA TM1116, (Oct。1947)

Eberhard Koppe, "Methoden der nichtlinearen Elastizitatstheorie mit Anwendung auf die dunne Platte endlicher Durchbiegung, " Z. angew: Math. Mech。36,. (Nov。1956), pp。455-462

A. Kromm and K. Marguerre, "Behavior of a Plate Strip under Shear and Compressive Stresses beyond the Buckling Limit," NACA TM $870 ;$ (1938)

H. L。 Langhaar, R。E. Miller, A: P.: Boresi, "Deflections of Non-Homogeneous Anisotropic Elastic Plates Subjected to Heating," Univ。 of Ill." (August. 1958) (AD 202755 )

Samuel Lerner and William Prager, "On the Flexure of Plastic Plates," Brown Univ。TR 50 (Sept. 1959) AD 226258

Samuel Levy, "Bending of Rectangular Plates with Large Deflections," NACA Report 737, (1942), pp.1-19

Samuel Levy, "Buckling of Rectangular Plates with Built-in Edges 。" J. Appl。:Mech。, 9, (Dec。1942), pp。171-174

Samuel Levy, "Square Plate with Clamped Edges under Normal Pressure Producing Large Deflections," NACA Report 740 (1942)

H. G. Lew, J.A. Fox and T. T. Loo, "Large Deflection of Curved 'Plates," NACA TN 3684 (Oct. 1956)

Eugene E。 Lundquist and Elbridge Z. Stowell, "Critical Compressive Stress for Flat Rectangular Plates Supported along All Edges and Elastically Restrained against Rotation along the Unloaded Edges, " NACA.Report 733, (1942)

Eugene E. Lundquist and Elbridge Z. Stowell, "Restraint Provided a Flat Rectangular Plate by a Sturdy Stiffener along an Edge of the Plate," NACA Report 735 (1942)

S. V. Manson, "Temperatures Thermal Stress, and Shock in Heat-Generating Plates of Constant Conductivity and of Conductivity That Varies Linearly with Temperature," NACA TN 2988 (July 1953)

Marguerre, Karl, "The Apparent Width of the Plate in Compression, " NACA TN 833 (1937) 
Karl Marguerre, "On the Application of the Energy Method to Stability Problems," NACA TM. 1138, (Oct. 1947)

Karl Marguerre, "Zur Theorie Der Gekrummten Platte Grosser Formanderung., " Proc. 5th Int. Cong. Appl. Mech. (1938)\% pp. 93-101

E. F. Masur, "On the Analysis of Buckled Plates," Proc。3rd U. S. Nat'1 Cong. Appl. Mech (1958), pp. 411-417

J. Mayers, Bernard Budiansky, "Analysis of Behavior of Simply Supported Flat Plates Compressed beyond the Buckling Load into the Plastic Range," NACA TN 3368:(Feb. 1955)

William A. Nash, James R. Modeer, "Certain Approximate Analyses of the Nonlinear Behavior of Plates and Shallow Shells," Univ. of Fla., (July 1959), (AD 226 736)

J. Nowinski, "Note on an Analysis of Large Deflections of Rectangular Plates," Univ. of Wis., MRC TSR 34, (August 1958), (AD 203 819)

J. Nowinski, "Some Mixed Boundary-Value Problems for Plates with Large Deflections," Univ, of Wisc., MRC TSR 42, (Oct. 1958), (AD 207 320)

K. Ozden, "Biegung dunner Platten und Variationssatze bei einem nichtlinearen Elastizitatsgesetz," Ing.-Archiv, 24, (1956), pp. 133-147

Sharad A. Patel and B. Venkatraman, "Creep Bending of Compressible Plates," Poly. Inst. Brooklyn PR 590 (April 1961). (AD 259 355)

William Prager, "The General Variational Principle of the Theory of Structural Stability," Q. Appl. Math. 4, (Jan. 1947) pp.378-384

Eric Reissner, "On Bending of Elastic Plates," Q. Appl. Math. , 5 , (April 1947), pp. 55-68

J. Lyell Sanders, Jr., Harvey G. McComb, Jr., and Floyd R. Schlechte, "A Variational Theorem for Creep with Applications to Plates and Columns," NACA TN 4003 (May 1957)

Josef Singer, M. Anliker, and S. Lederman, "Thermal Stresses and Thermal Buckling," WADC TR 57-69.(April 1957), (AD 118:287)

N. C. Small, "Pressure and Thermal Stress Analysis of the Plate-Type Fuel Subassemblies," Proc. 3rd U. S. Nat'l Cong. Appl. Mech. (1958), pp. 451-459

Manuel Stein, "Loads and Deformations of Buckled Rectangular Plates," NASA TR R-40.(1959) 
Elbridge Z. Stowell, "A Unified Theory of Plastic Buckling of Columns and Plates," NACA Report 898 (1948)

G. A. Thurston, "Bending and Buckling of Clamped Sandwich Plates:," J. Aero Sci. . 24, (June 1957), pp. 407-412

William C. Walton, Jr., "Applications of a General Finite-Difference Method for Calculating Bending Deformations of Solid Plates," NASA TN D-536

;(Nov. 1960)

Chi-Teh Wang, "Non-Linear Large-Deflection Boundary - Value Problems of Rectangular Plates," NACA TN 1425, (March 1948)

Jerome Weiner, "An Elastoplastic Thermal-Stress Analysis of a Free Plate," J. Appl. Mech., 23, (Sept. 1956), pp. 395-402

H. J. Weiss, and G. H. Handelman, "A Minimum Principle for Structural Stability,": Q. Appl. Math. 8, (Jan. 195l), pp. 395-401

M. L. Williams, "Large Deflection Analysis for a Plate Strip Subjected to Normal Pressure and Heating," J. Appl. Mech., 22, (Dec! 1955), pp. 458-464

M. L. Williams, "Further Large-Deflection: Analysis for a Plate Strip Subjected to Normal Pressure and Heating," J. Appl. Mech., 25, (June 1958) pp. $251-258$

Noboru Yamaki, "Postbuckling Behavior of Rectangular Plates with Small Initial Curvature Loaded in Edge Compression," J. Appl. Mech. '. 26 (Sept. 1959), pp.407-414

Noboru Yamaki, "Postbuckling Behavior of Rectangular Plates with Small Initial Curvature Loaded in Edge Compression-continued," J. Appl . Mech. , 27. (June 1960), pp. 335-342 


\section{APPENDIX B}

\section{REVIEW OF EXI3TING DATA AND}

APPLICATION TO THERMAL ANALYSIS 


\section{B. I GENERAL CONSIDERATIONS}

In the selection of the proper parameters to be used in the thermal evaluation of the rippling problem, consideration must be given to all forms of available information. This includes the mathematical analysis presented in this report plus existing experimental results, manufacturing and post-irradiation measurements of fuel elements, and stainless steel- $\mathrm{UO}_{2}$ property data. Compilation of this information into a form suitable for use in a revised steady state and transient analysis of SM-IA (Core I and II) requires that a degree of conservatism be maintained to account for the inherent uncertainties associated. with such small quantities of data.

\section{B.1.1 Small Deflection Theory}

As previously explained in the report, the use of small deflection theory to mathematically predict the resulting channel closure is in itself a conservative approach since it would be physically impossible to obtain deflections which are much larger than the fuel plate thickness without having some appreciable changes occurring in the plate. If this theory is used to determine the amount of additional deformation resulting from thermal heating of an initially curved plate, the predicted results will, in general, be conservative as the magnitude of the deflection increases.

\section{B.1.2 Fuel Plate Support}

Likewise, the assumption that the plate is simply supported rather than fixed at the sidewalls, would be conservative if in fact significant restraint is imposed by the sidewalls. This can be seen by determining the average value of the deflection associated with the above methods of support.

1. Simply supported

$$
\begin{aligned}
& \mathrm{w}=(A+B) \sin (\pi \mathrm{y} / \mathrm{b}) \\
& w_{\text {avg }}=1 / \mathrm{b} \int_{0}^{b}(A+B) \sin (\pi y / b) d y=(2 / \pi)(A+B)
\end{aligned}
$$

2\%. Fixed edge

$$
\begin{aligned}
& \mathrm{w}=(\mathrm{A}+\mathrm{B})[\mathrm{b}[1 / 2-1 / 2 \cos (2 \pi \mathrm{y} / \mathrm{b})] \\
& w_{\text {avg }}=(1 / b) \int_{0}(A+B) \quad[1 / 2-1 / 2 \cos (2 \pi \quad y / b)] d y \\
& \text { b } \\
& \mathrm{w}_{\text {avg }}=(1 / 2)(A+B)
\end{aligned}
$$

Since the value $2 / \pi$ is greater than: $1 / 2$, the use of a simply supported 
model results in a smaller average coolant channel for the thermal analysis.

\section{B.1.3 Mechanical Properties}

The use of pre-irradiated mechanical properties also tends to be conservative since the stainless steel- $\mathrm{UO}_{2}$ matrix becomes more brittle, and hence less susceptible to bending, with increasing irradiation (2).

If more ductile properties are assumed to exist throughout core lifetime, the calculated deflections will be higher and thus the effect on core thermai performance greater.

\section{B. I.4 Adjacent Fuel Plate Rippling}

Another assumption which must be made for a conservative estimate of the effects of rippling on core thermal performance is in regard to the deflection or rippling of adjacent fuel plates. It has previously been shown (3) that for internal channels the worst condition for pressure drop and flow consideration occurs when two adjacent plates are $180^{\circ}$ out of phase. This is also true of a lattice channel between two stationary elements where the outer plates of two adjacent fuel elements are parallel. Since rippling is usually more severe on outer plates this is potentially the worst location from a thermal standpoint. Figure B.I illustrates the possible conditions which could exist for the internal channels and external lattice passages.

For the outer channels of a control rod element; the minimum clearance is independent of the phase of an adjacent "fuel plate" since this channel is bounded on one side by the square. control rod "tube". It is, however, dependent on the tolerance of the control rod tube.

If the previously described items are all used conservatively in determining the effect of rippling on the thermal performance of the core, the results should be very conservative since it is highly: improbable that all would simultaneously occur in an adverse manner.

\section{B.2 INITIAL DISTORTION}

Since the final channel spacing for a rippled fuel element is the initial spacing minus the final (hot) deflection of the adjacent fuel plates, and the final deflection is directly proportional to plate temperature and initial deflection, it is extremely important to establish the magnitude of the initial rippling as well as the initial spacing for the limiting lattice passage.

\section{B.2.1 Manufacturing Tolerances}

Channel tolerance specifications for SM-lA fuel elements generally limit deviations. to $\pm 10 \%$ of the nominal dimension $(4),(5),(6),(7)$ (i.e. 0.133 in. \pm .013 in.). Waivers (4) have been given for Core II (SM-1A) in which deviations 


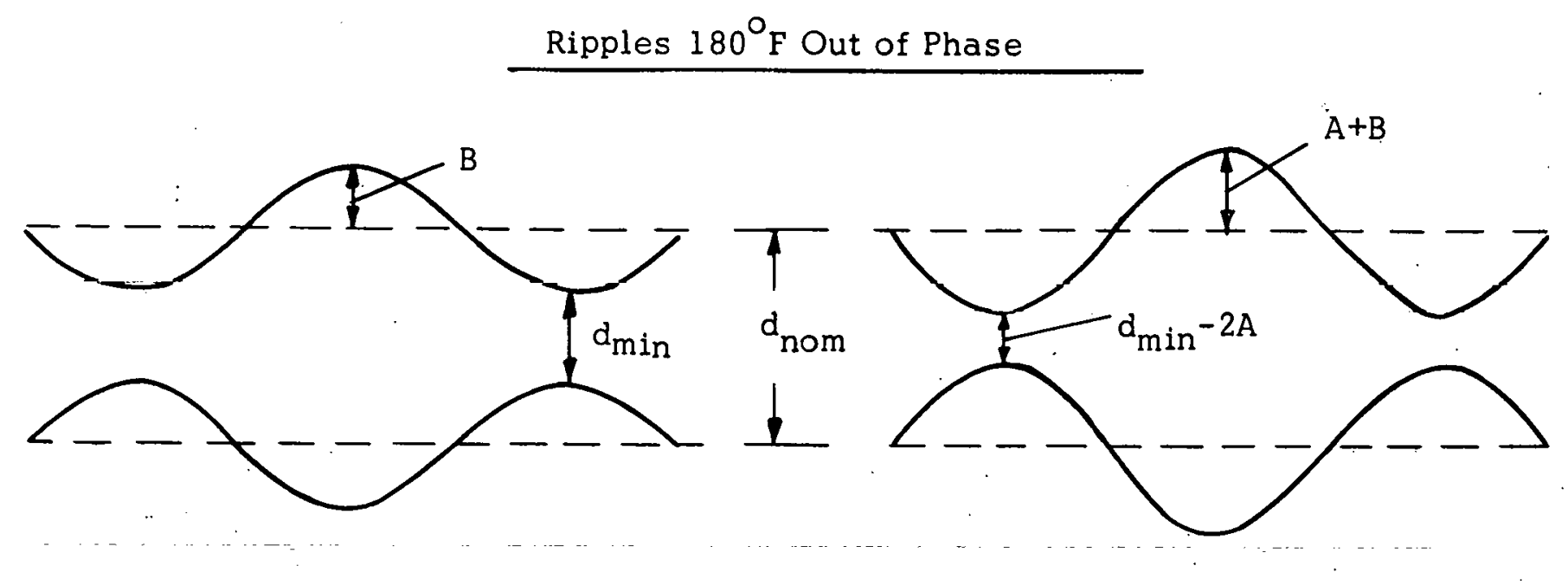

a) Fabricated Condition

b) Operating Condition

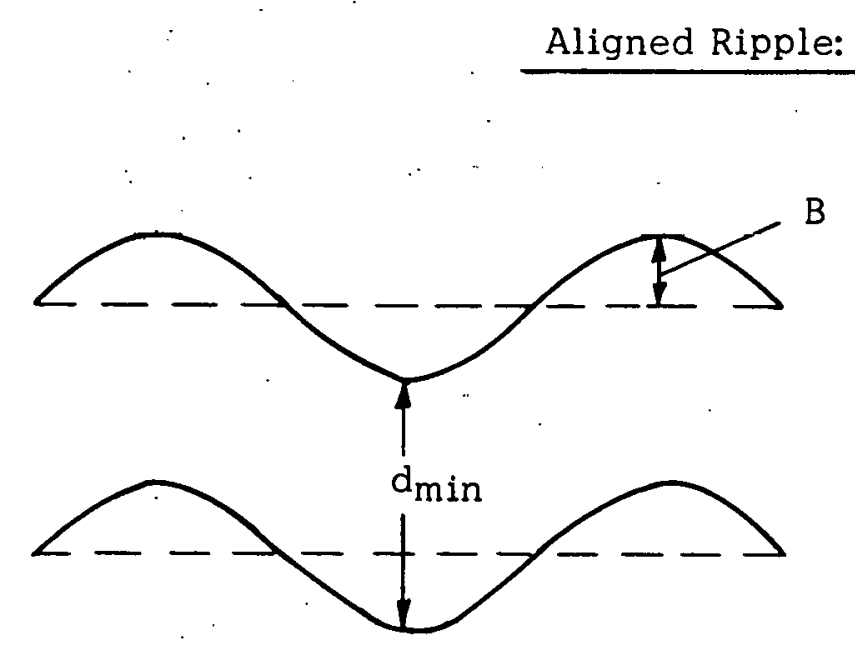

a) Fabricated Condition

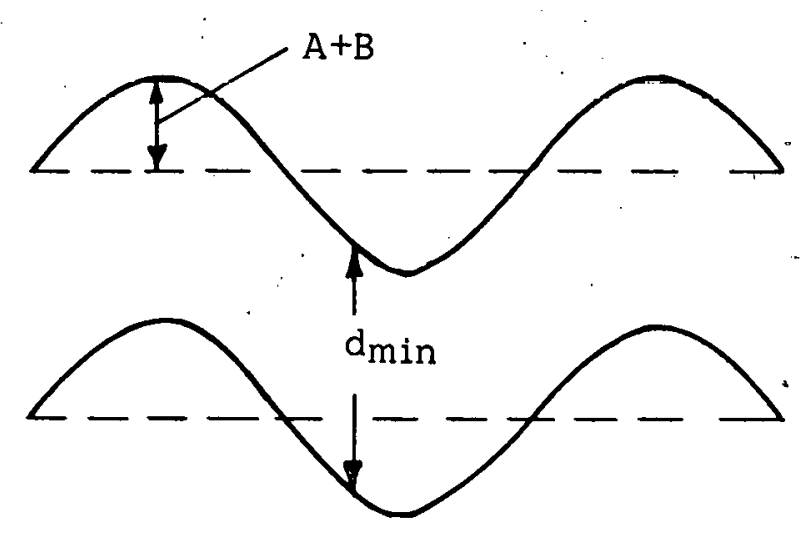

b) Operating Condition

Figure B.1. Schematic Representation of Internal Channels and Lattice Channel Longitudinal View 
of \pm 0.020 in. were allowed provided no one channel had more than a 0.020 in. variation: (this in effect would reduce the minimum channel clearance: but would also only permit \pm 0.010 in. rippling amplitudes).

Calculations (8) have also been made on the minimum obtainable external channels. and indicate that it is possible to have minimum clearances of 0.094 in. However, such dimensions occur in channels bordered by one active fuel plate and a structural member. The increased channel closure resulting during "hot" operation would not be as severe as a case in which the channel is composed of two active fuel plates. This case would occur when two stationary elements are aligned so that the fuel plates in both elements are parallel (lattice passages). The minimum dimension for this situation has been shown ${ }^{(8)}$ to be 0.118 in. Since the maximum dimension could by the same analysis be 0.148 in. , the peak to peak amplitude of the initial ripples, assuming symmetry, is 0.015. in.

This value is in fair agreement with the results of ORNL measurements (9) taken at Fort Greely and the SM-1 measurements taken by the Army at Fort Belvoir (10). Approximately $65 \%$ of the readings taken on $96 \mathrm{SM}-1 \mathrm{~A}^{(9)}$ fuel elements (top and bottom) had less than a. 0.015 in. peak: to peak variation while another $20 \%$ fell between $0.015 \mathrm{in}$. and $0.025 \mathrm{in}$. Based.on these results, 13 fuel elements were recommended for specific core placement $(8)$ in low power regions (See Table B.1) while the remaining elements were released for unrestricted core placement. Thus it can be seen that the maximum peak-to-peak initial ripple amplitude as defined in Section 1.0 , can be considered to be between 0.020 in. and 0.025 in.

\section{TABLE B。1}

$\frac{\text { SPECIFIC PLACEMENT LOCATION OF SM-1A CORE I ELEMENTS }}{\text { Maximum }}{ }^{(8)}$
Element Number
Ripple Amplitude, in。

$3 S$
$15 S$
$16 S$
$1.7 S$
$18 S$
215
235
245
335
385
435
50
52 


\section{B.2.2 Number of Ripples Per Plate}

The number of complete cycles which occur, that is, the number of complete ripples per plate, varies from one to six. An examination of the data taken at Fort Greely ${ }^{(9)}$ shows that an average of from four to five ripples will occur. Figures B.2 and B.3 show typical plots of the data taken.

As discussed, within the report, the number of half sine waves which will occur in a very long, simply supported plate is approximately given by the expression

$$
n=a / b
$$

Using the dimensions of the SM-1A fuel element gives

$$
\mathrm{n}=23 / 2.778=8.3
$$

The number of complete. waves is then approximately four, in good agreement with the observed variations.

Similar measurements are planned for SM-1A Core II during the final inspection of the core.

\section{B.2.3 End-of-life Initial Distortion}

At the end-of-life an additional factor must be considered in establishing the deflection amplitudes at this point in core lifetime. This is an increase in the "initial" distortion resulting from core operation. Although not a true initial ripple, it would represent a pseudo point from which ripple growth would occur if the reactor were shut down and then brought back to full power near the end of core life.

Although some evidence exists, (11) that this increased distortion results from an increase in the length of the fuel plate caused by fuel growth, there is also the possibility that the increase: in ripple amplitude is a result of inelastic deformations resulting during core operation such as plastic flow and hardening of the matrix due to irradiation damage.

Measurements made at Oak Ridge ${ }^{(12)}$ on two fuel elements showed a decrease: in the minimum channel dimension from 130 mils to 120 mils in the control rod element (CR-13), and from 130 mils to 124 mils on the stationary element (S-72). These measurements were made after 10.5 MWYR of operation or approximately two-thirds of design burnup.

Similar measurements ${ }^{(13)}$ were made on a stationary element (S-79) after 16.4 MWYR of operation. Measurements in this element indicated 42 and $57 \mathrm{U}-235$ atom percent depletion for average and maximum values of burnup. Although no pre-irradiation rippling measurements are available it can be assumed that they fell 


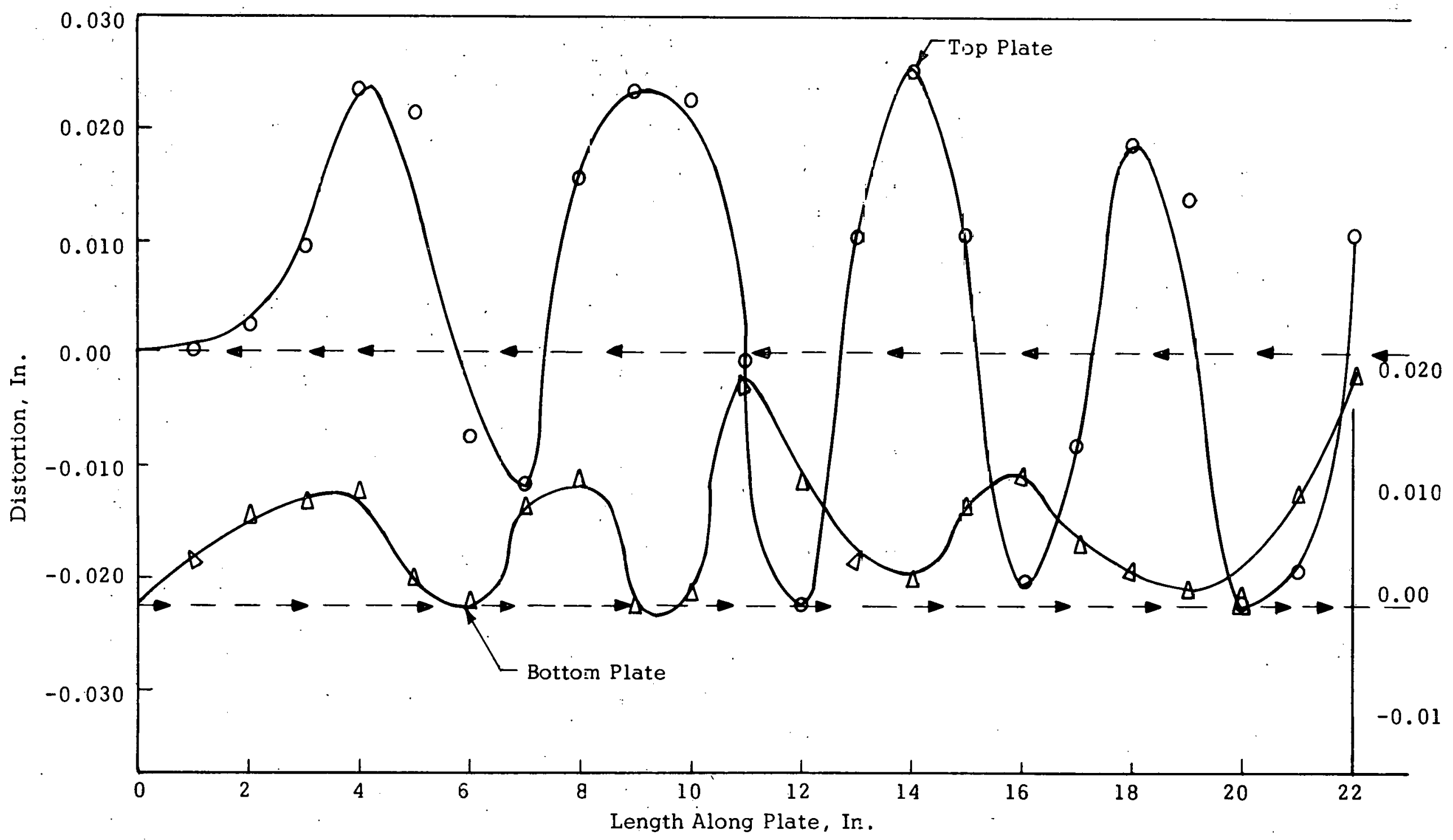

Figure B.2. Initial Rippling of Element $17-$ SM-1A 


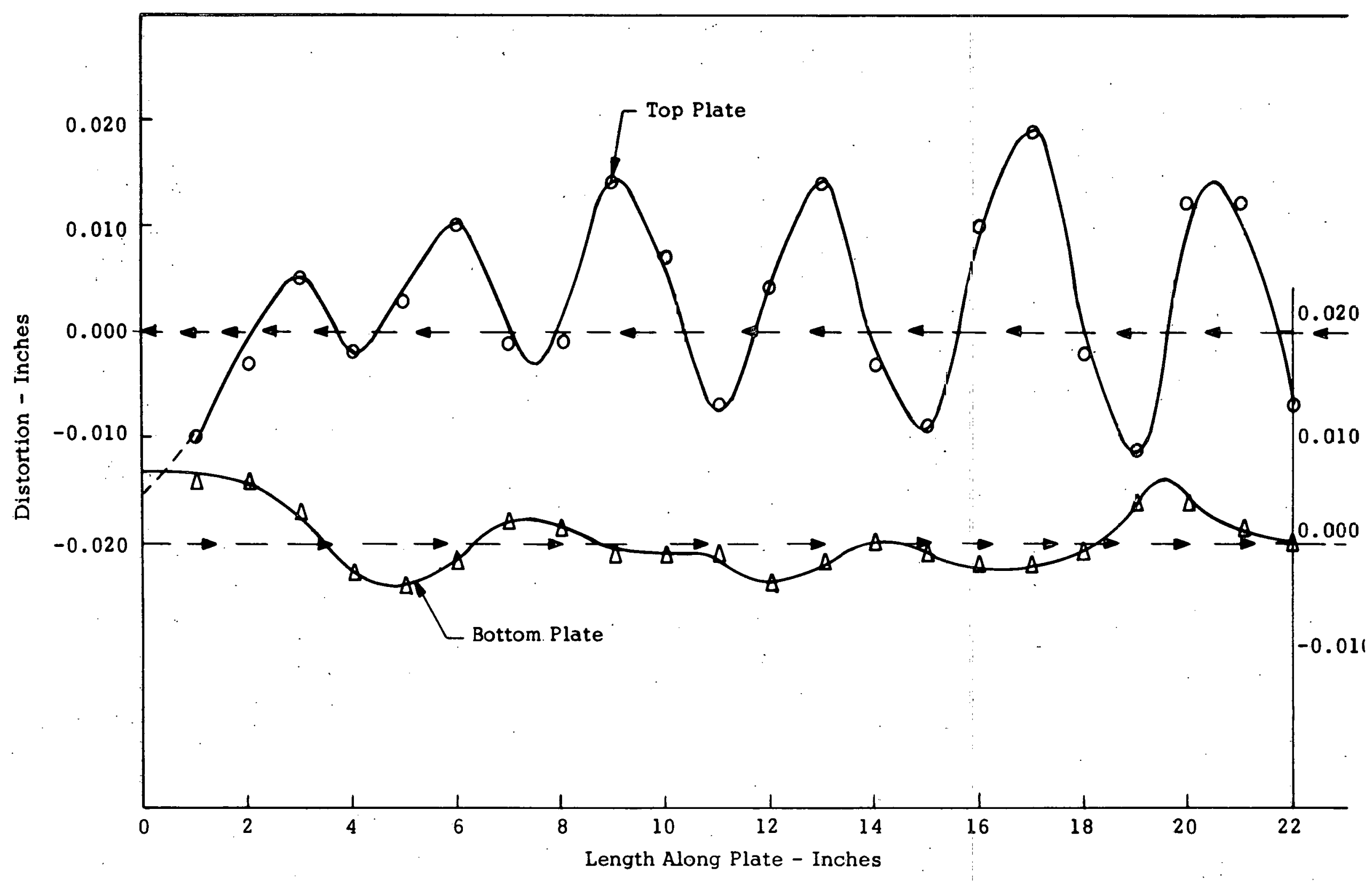


within the fabrication tolerances. Post-irradiation measurements indicated a maximum deviation of 0.035 in.: however, the maximum peak-to-peak amplitude of rippling was 0.040 in. to 0.042 in. This represents an increase of about $0.015 \mathrm{in.}-0.017 \mathrm{in}$. over the $0.025 \mathrm{in}$. initial values mentioned in the previous section. It is not believed that SM-1 Core I was as bad as the SM-IA Core I.

It should be noted that while this represents a significant increase in the initial amplitude of the ripples, the maximum temperature differential at this time in life is less than at the beginning-of-life. Table B.2 shows the comparative values which distinguish these two design points.

\section{TABLE B.2}

\section{COMPARISON OF RIPPIING PARAMETERS AT BEGINNING AND END OF CORE LIFETIME}

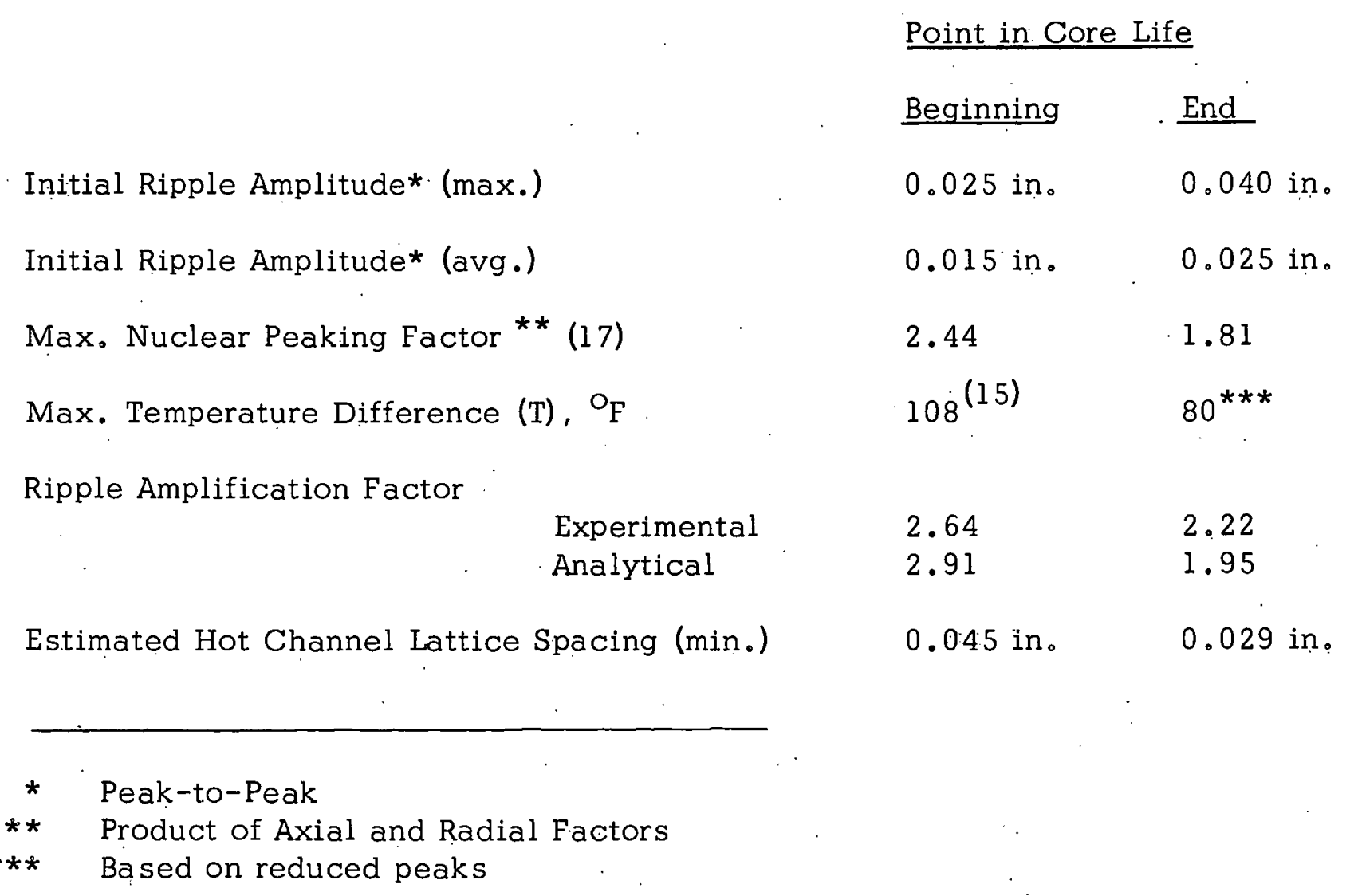

\section{B.2.4 Ripple Amplification Factor}

The amount of additional rippling caused by heating is proportional to the initial ripple and the temperature differential between the heated and unheated portion of the fuel element. If an amplification factor is defined as the ratio of the final deflection to the initial deflection $(A+B) / B$, it becomes useful in describing the rippling problem. 
Test results (14) made on welded 0.040 in. fuel plates showed that the distortion from thermal testing resulted in a amplification factor of approximately two for a temperature differential of between 100 to $118^{\circ} \mathrm{F}$. However, this value is considered unconservative since the plate thickness was 40 mils

$\because \quad$ rather than 30 mils 。

Recent tests (15) made a reference brazed fuel element indicate that, for temperature differences in this range $\left(100-120^{\circ} \mathrm{F}\right)$, the deflection increased at a rate of $1.52 \times 10^{-2}$ in. per inch of initial deflection per ${ }^{\circ} \mathrm{F}$ temperature. differential. The amplification factor for this case is thus

$$
(A+B) / B=1+\left(1.52 \times 10^{-2} \mathrm{~T}\right)
$$

where $\mathrm{T}$ is the temperature differential between the sidewall and the fuel plate. This also is in falr agreement with previous results on a solid 0.030 in. stainless plate. (16)

From the mathematical model (Section 4.5 ) the amplification factor was found to be

$$
A+B / B=\frac{1}{1-(1.733 \mathrm{~T} / 285)}
$$

The difference between the two methods is shown on Table B.l along with the minimum estimated hot channel spacing determined by the following method:

$$
D_{\min }=D_{f a b}-2(A+B)
$$

where

$$
\begin{aligned}
& D_{\mathrm{fab}}=\text { minimum fabricated dimension }(0.118 \mathrm{in} .) \\
& \mathrm{A} \quad=\text { additional deflection } \\
& \mathrm{B} \quad=\text { initial deflection }
\end{aligned}
$$

Thus, for the two cases shown, the minimum channel spacing is 0.045 in. and $0.029 \mathrm{in}$. for the beginning and end of life respectively. The minimum value of $0.029 \mathrm{in}$. is still above the $0.018 \mathrm{in}$. "minimum allowable" value selected in APAE Memo-300。(4)

Because of the non-uniformity of the ripple amplitude, it is doubtful that all of the ripples in any one channel would result in minimum channel closures of this magnitude. A more realistic interpretation of the data would be to assume that all but one of the ripples were of average size and that one maximum ripple occurs at the most critical thermal point in the channel. 


\section{B.3 APPLICATION TO THERMAL ANALYSIS}

\section{B.3. I Description of the Rippled Coolant Channel}

Although some rippling measurements are available, (10), (12), (13), (18) they are in general only indications of what the dimensions of a particular coolant channel might be. The orientation of the adjacent element and the end-of-life condition are important factors which must also be considered in the explicit channel description at a given location.

For the beginning-of-life analysis, such information can be obtained, (8) provided allowances are made for alignment tolerances. However, at the endof-life, the actual condition existing can only be estimated and, without the actual channel measurements, it must be assumed that the worst combination of all the adverse items previously mentioned will occur at the thermal "hot spot" in the core.

If the following assumptions are made

1. Average number of ripples per channel is four

2. Maximum ripple amplitude (hot peak to peak) is $0.073 \mathrm{in}$. at the beginning of life and $0.089 \mathrm{in}$. at the end of life

3. Average ripple amplitude (hot peak to peak) is 0.044 in. at the beginning of life and 0.056 in, at the end of life

4. Ripples on adjacent fuel elements are $180^{\circ}$ out of pha se

than a schematic representation of the "hot" rippled channel can be constructed (Fig. B.4) with the maximum ripple occurring at the location of maximum flux.

\section{B.3.2 Thermal Analysis of the Rippled Channel}

The greater magnitude of rippling at the end-of-life will probably be more than off set by the smaller nuclear factors existing. It does not appear that this condition will be more limiting than the beginning-of-life. However, to ascertain whether or not this supposition is correct, both cases should ultimately be analyzed.

A transient two-dimensional, hydrodynamic model (19) has been programmed for use on the Philco 2000 digital computer. Although the version of the code which is currently available does not contain an explicit description of variable channel spacing, it is possible to approximate the condition of a ripple channel by appropriate choice of input parameters which affect the flow redistribution, enthalpy rise and departure from nucleate boiling ratio (DNBR) calculations. This can be accomplished by definining correction factor relating the local thickness to the nominal channel thickness $d_{l o c} / d_{n o m}$. This correction factor is 


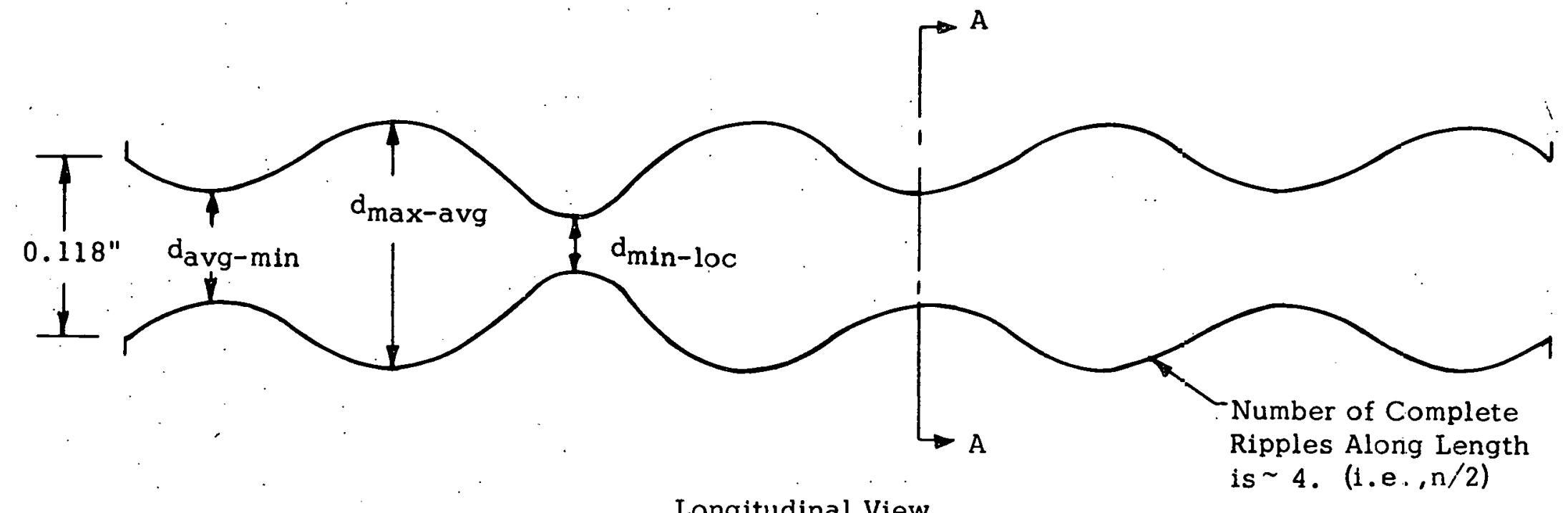

Longitudinal View

\begin{tabular}{lccc} 
Symbol & & \multicolumn{2}{c}{ Veginnng } \\
$n$ & $\frac{8}{\text { End }}$ & $\frac{8}{8}$ \\
$d_{\text {min-10c }}$ & 0.045 & & 0.029 \\
$d_{\text {min-avg }}$ & 0.074 & 0.063 \\
$d_{\text {max-avg }}$ & 0.162 & 0.173 \\
Lenigth & $23^{\prime \prime}$ & $23^{\prime \prime}$
\end{tabular}

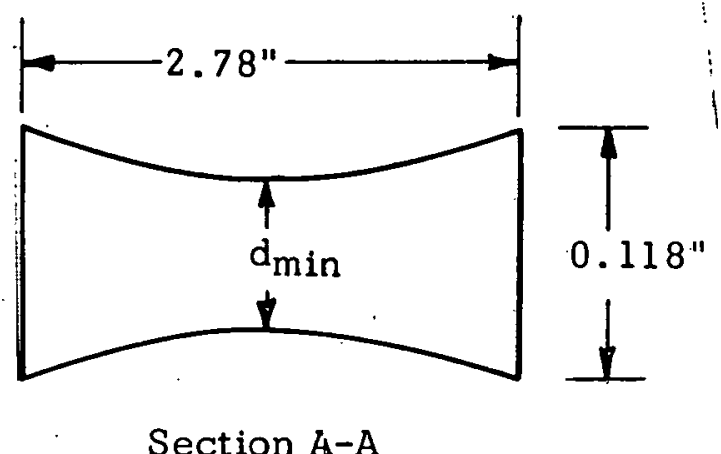

Figure B.4. Schematic of Rippled Coolant Channel Under Operating Conditions 
then applied to the local friction factor, local heat flux and local DNB correction factor so that the results will approximate the analysis of a rippled channel in which the geometry was described explicitly.

Using this procedure, steady state and transient analysis of the SM-1A may be made to determine the effect of rippling on core thermal performance.

\section{B. 4 SUMMARY}

Sufficient experimental and manufacturing data exists and can be coupled with the mathematical solution presented in the body of this report to predict conservatively the rippled channel geometry which can be expected at beginning and end of core lifetime. A thermal analysis can then be performed using the TITE(19) two-dimensional digital model to determine the effect of the rippling on core performance.

\section{B. 5 APPENDIX REF ERENCES}

1. Shober, F.R., "The Effect of Nuclear Radiation on Structural Metals," REIC Report No. 20, September 15, 1961 .

2. "Materials," Power Reactor Technology, Vol. 5, Number 1, Section VIII, December 1961 .

3. Brondel,.J.๑。." "Supporting Analyses and Derivation of Dimensional Tolerance Specifications for Core II of SM-1A and PM-2A, " APAE Memo-300, Nuvember 3,1901 .

4. Marimpietri, A., "Specifications and Fabrication Procedures for SM-1A Core II Control Rod. Fuel Element," APAE Memo-257, May 13, 1960.

5. Marimpietri, A., "Specifications and Fabrication Procedures for SM-1A Core II Stationary Fuel Elements," APAE Memo-258, May 13, 1960 。

6. Cunningham, J.E., et al, "Specifications and Fabrication:Procedures for APPR-1 Core II Stationary Elements, " ORNL-2649, February 19, 1959.

7. Cunningham, JoE。, et al, "Specifications and Fabrication: Procedures for APPR-1 Core Il Control Rod Elements," ORNL-2726, July.29, 1959.

8. Brondel, J.O..." "Supporting Analysis for Thermal Suitability of Fuel Elements for SM-1A.Core I Loading," APAE Memo-299, January: 10, 1962.

9. Beaver, R.J., "Report of Examination of 39 Stationary Fuel Elements at Fort Greely, Alaska," Oak Ridge National Laboratory ; August 23, 1961. 
10. Letter, I.M. Adler of New York Operations Office, AEC, to W.S. Brown of Alco Products, dated August 9, 1961, file: RA:IMA:2639/3.1.10, subject: Inspection of SM-1 Spare Elements.

I1. Zimmerman, D.L., "Irradiation and Post-Irradiation of Examination of APPR Type Fuel Elements, " Vallecitos Atomic Laboratory Report GEAP-3292, November 1.959。

12. Staff, Oak Ridge National Laboratory, "Army Package Power Reactor Project Annual Progress Report for Period Ending January 31, 196I," ORNL-2907.

13. Schaffer, L。D., "Army Reactors Program Progress Report," ORNL-3231, February 14, 1962.

14. Christenson, J.A., "Thermal Stress Testing of SM-2 Fuel Elements Interim Technical Report, January 1, 1959 to January 1, 1961," APAE Memo-239, February 9, 1960。

15. Gebhardt, F.G., "Thermal Stress Testing on Type 1 Single Fuel Plates," APAE Memo-317, to be issued June 1962 .

16. Bradley, P.L., "Investigation of Local Boiling," APAE-88, June 20, 1961 。

17. Letter: L.D. Schaffer, Oak Ridge National Laboratory, to Capt. S.. R. Meeken, Division of Reactor Development, AEC, Subject: "Trip Report to National Reactor Meeting Station, "October 24, 1961。

18. Lois, L。, et al, "Summary Report of Analysis of Physics Measurements Performed on SM-1 Core I, "APAE-103, March 30, 1962.

19. Miller, R.J., and Pyle, R。S... "TITE - A Digital Program for the Prediction of Two-Dimensional Two-Phase Hydrodynamics, "WAPD-TM-240, February: 1962 。 